\title{
MANIFESTAÇÕES DA COVID-19 EM COLABORADORES DA SAÚDE PÚBLICA DE AÇAILÂNDIA - MA
}

\section{ARTIGO ORIGINAL}

SANTOS, Ada Marinho dos ${ }^{1}$, BARBOSA, Andressa Oliveira ${ }^{2}$, GOMES, André da Silva ${ }^{3}$

SANTOS, Ada Marinho dos. BARBOSA, Andressa Oliveira. GOMES, André da Silva. Manifestações da COVID-19 em colaboradores da saúde pública de Açailândia - MA. Revista Científica Multidisciplinar Núcleo do Conhecimento. Ano 06, Ed. 08, Vol. 01, pp. 89-122. Julho de 2021. ISSN: 2448-0959, Link de acesso: https://www.nucleodoconhecimento.com.br/saude/manifestacoes-da-covid-19, DOI: 10.32749/nucleodoconhecimento.com.br/saude/manifestacoes-da-covid-19

\section{RESUMO}

A COVID-19 afeta diferentes pessoas e sua ação atua de forma distinta, assim, boa parte das pessoas infectadas não precisam ser hospitalizadas. Os sintomas mais comuns são: febre; tosse seca; cansaço. Nesse viés, a questão norteadora do referido trabalho consiste em descobrir qual foi o comportamento dos sintomas da COVID-19 em colaboradores da saúde pública de Açailândia - MA. Este trabalho tem como objetivo disponibilizar um levantamento de dados dos funcionários acompanhados com sintomatologia da COVID-19 no período de abril a outubro de 2020 sobre o comportamento dos sintomas da COVID-19 em profissionais de saúde de uma Instituição Pública. Este estudo descritivo trata-se de uma pesquisa documental, quantitativa, fundamentada em dados secundários, tendo como base 0

\footnotetext{
${ }^{1}$ Especialista em Saúde Pública (UEMA) e Especialista em Saúde da Família (IBPEX), concluindo Mestrado em Educação para Saúde (Instituto Politécnico de Coimbra - IPC, Portugal) - Enfermeira, especialista em Gestão em Saúde (UEMA), Nefrologia Multidisciplinar UFMA - Especialista em Hematologia Clínica.

${ }^{2}$ Graduação.

${ }^{3}$ Graduação.
}

RC: 93206

Disponível em: https://www.nucleodoconhecimento.com.br/saude/manifestacoes-da- 
período de março a outubro de 2020, com uma amostragem de 256 funcionários (129 responderam ao questionário) de uma instituição pública localizada no município de Açailândia/MA. Válido informar que nos meses de maior contaminação não havia protocolos e medicamentos específicos, e por ser uma doença recente, a terapêutica medicamentosa e orientações se valeram do risco benefício. Além disso, um fator importante se deve ao fato de boa parte dos profissionais iniciar o tratamento precocemente. Os resultados demonstraram que a maioria dos profissionais que apresentaram sintomas da COVID-19 são do sexo feminino, totalizando $82,9 \%$. Em relação às medicações usadas durante o tratamento destacase a azitromicina $(79,8 \%)$, dipirona $(63,6 \%)$, ivermectina $(64,3 \%)$, entre outros. A maioria dos trabalhadores, ou seja, 62,8\% não possuíam nenhuma doença crônica. Além disso, foi constatado que $92,2 \%$ não precisaram ser internados por complicação após COVID-19. Por fim, conclui-se que, se iniciado precocemente o tratamento e quando há acompanhamento adequado os riscos de complicações são reduzidos. Em relação à sintomatologia, as principais queixas foram: febre; tosse seca; dor de cabeça; secreção nasal/espirros; dor de garganta; dificuldade respiratória; dor no corpo; ausência de paladar ou boca amarga; fraqueza; insônia; dor torácica; dor na região lombar; dor ao urinar; redução da libido sexual, entre outras.

Palavras-chave: COVID-19, Comportamento, Sintomas, Tratamento, Profissionais de Saúde.

\section{INTRODUÇÃO}

No final do ano de 2019, mais precisamente na cidade de Wuhan na China começaram a surgir um número muito elevado de casos de pneumonia, que posteriormente chamaram a atenção do mundo para essa nova doença. Desse período em diante tem-se discutido muito sobre o novo coronavírus (SARS-CoV-2) e a doença que ele provoca (SANTOS et al., 2020).

RC: 93206

Disponível em: https://www.nucleodoconhecimento.com.br/saude/manifestacoes-da- 
De acordo com o World Health Organization (2020) atualmente existem casos confirmados da COVID-19 espalhados por todos os continentes. Os termos oficiais referentes ao novo coronavírus e a COVID-19 tiveram anúncio por meio da Organização Mundial de Saúde no dia 11 de fevereiro de 2020, definidos da seguinte forma: Doença - COVID-19 (do inglês "Coronavírus Disease" 2019); Vírus SARS-CoV-2 (do inglês "Severe Acute Respiratory Syndrome Coronavirus 2").

De acordo com Brasil (2020), mesmo a maior parte das pessoas acometidas pela COVID-19 tenham sintomas leves ou não complicados, outras já desenvolvem doença grave que requer oxigenoterapia (14\%), e aproximadamente 5\% precisam de tratamento em Unidade de Terapia Intensiva (UTI). Além disso, em relação aos doentes críticos, a grande maioria precisa de ventilação mecânica.

Com o surgimento de diversas dúvidas sobre essa doença e sua mutação, vindo acompanhada de um leque muito variado de informações sobre o assunto, é preciso dar o enfoque necessário à enfermagem bem-informada e preparada para atuar no atendimento dos novos casos da doença na assistência especializada e em todos os níveis de atenção de forma segura (OLIVEIRA et al., 2020).

A COVID-19 afeta diferentes pessoas e sua ação atua de forma distinta. Uma boa parte das pessoas infectadas praticamente não precisam ser hospitalizadas. Sendo assim, os sintomas mais comuns são: febre; tosse seca; cansaço. Por outro lado, existem outros sintomas que podem ser considerados: dor de cabeça, diarreia, dor de garganta, dores, perda de paladar ou olfato, conjuntivite, desconfortos, erupção cutânea na pele e descoloração dos dedos das mãos ou dos pés (TEIXEIRA et al., 2020).

Os profissionais de saúde representam ativamente um grupo de risco para a Covid19, pois diariamente são expostos aos pacientes infectados, o que faz com que estejam suscetíveis a uma grande carga viral (milhões de partículas de vírus). Além disso, estão expostos a uma alta carga de estresse ao examinar esses pacientes,

RC: 93206

Disponível em: https://www.nucleodoconhecimento.com.br/saude/manifestacoes-da- 
pois muitos estão em estado grave, em situações inadequadas (SANTOS et al., 2020).

É preciso destacar que a força de trabalho em saúde não é homogênea, porquanto destaca-se a diferença de gênero, raça e classe social, estruturantes do acesso aos diversos níveis e cursos de formação profissional, atuando da mesma maneira das relações de trabalho nos serviços de saúde ao mesmo tempo que as oportunidades de inserção no mercado de trabalho (TEIXEIRA et al., 2020).

Os profissionais e os trabalhadores de saúde estão diretamente na linha de frente, com maior risco de contágio, a diferença que define estes agentes de saúde determina formas diferentes de exposição, tanto ao risco de contaminação quanto aos fatores associados às condições de trabalho (TEIXEIRA et al., 2020).

Nesse viés, a questão norteadora do referido trabalho consiste em descobrir qual foi o comportamento dos sintomas da COVID-19 em colaboradores da saúde pública de Açailândia - MA.

Por fim, o objetivo do presente estudo consiste em disponibilizar um levantamento de dados dos/as funcionários/as acompanhados/as com sintomatologia da COVID19 no período de abril a outubro de 2020 sobre o comportamento dos sintomas da COVID-19 em profissionais de saúde de uma Instituição Pública.

\section{METODOLOGIA}

Este estudo descritivo trata-se de uma pesquisa documental, quantitativa, baseado em dados secundários.

Segundo Gil (2011, p. 51), "a pesquisa documental vale-se de materiais que não receberam ainda um tratamento analítico, ou ainda, podem ser reelaborados de acordo com os objetivos da pesquisa". Por isso, por meio de ofício encaminhado ao responsável pela Instituição Pública de Saúde pode-se realizar o acompanhamento

RC: 93206

Disponível em: https://www.nucleodoconhecimento.com.br/saude/manifestacoes-da- 
com os profissionais que apresentaram sintomatologia da COVID-19, adquirindo informações pertinentes ao tratamento de cada profissional.

Por outro lado, para Richardson (1999), uma pesquisa quantitativa é caracterizada por empregar elementos de quantificação na coleta de informações e no tratamento das mesmas através de técnicas estatísticas. Assim, foi utilizado o Google forms doc para elaboração de gráficos, facilitando a visibilidade de informações para apresentação do quadro situacional da referida pesquisa.

O município em questão trata-se de Açailândia/MA, onde os habitantes se chamam açailandenses. O município se estende por $5806,4 \mathrm{~km}^{2}$ e contava com 113.121 habitantes no último censo (2020). A densidade demográfica é de 17,92 habitantes por km². Tem proximidade com Cidelândia e São Francisco do Brejão, a cidade de Açailândia é localizada a $64 \mathrm{~km}$ ao Norte-Oeste de Imperatriz. Está localizado a 231 metros de altitude, as coordenadas geográficas de Açailândia: Latitude: $4^{\circ}$ 57' 14" Sul, Longitude: $47^{\circ} 30^{\prime} 7^{\prime \prime}$ Oeste.

O clima é tropical. No inverno existe muito menos pluviosidade que no verão, sendo classificado como Aw. A temperatura média anual em Açailândia é $25.9{ }^{\circ} \mathrm{C} .1334$ mm é a pluviosidade média anual.

O estudo foi realizado com 256 funcionários (somente 129 responderam ao questionário) todos acompanhados pelo período de março a outubro de 2020. Os funcionários foram: enfermeiros, técnicos de enfermagem, técnico de radiologia, recepcionistas, porteiros, maqueiros, serviços gerais, setor administrativo, serviço de nutrição, bioquímicos, assistente social, assistente de laboratório, serviço de manutenção, motoristas e auxiliar de farmácia.

Diante disso, é importante destacar os critérios de inclusão e exclusão da presente pesquisa. Os critérios de inclusão foram: profissionais que apresentaram sintomas da COVID-19 e que estavam lotados na Instituição Pública de Saúde no município

RC: 93206

Disponível em: https://www.nucleodoconhecimento.com.br/saude/manifestacoes-da- 
de Açailândia/MA. Os critérios de exclusão foram: profissionais que não apresentaram sintomas da COVID-19 e que não estavam lotados na Instituição Pública de Saúde no município de Açailândia/MA.

O instrumento utilizado foi a análise documental, por meio do Google forms doc, onde foram coletadas informações dos funcionários, como, a idade, gênero, sintomas apresentados, mês que iniciou os sintomas sugestivos da COVID-19, medicamentos consumidos, vitaminas utilizadas etc. Dessa maneira, os arquivos da instituição que contém as informações sobre as diretrizes utilizadas em situação de pandemia foram indispensáveis para responder ao problema e aos objetivos.

A pesquisa foi realizada após aprovação do Comitê de Ética em Pesquisa (CEP), e respeitadas às normas de pesquisa envolvendo seres humanos, Resolução $\mathrm{n}^{\circ}$ 466/12 do Conselho Nacional de Saúde.

Os dados foram registrados e analisados por meio descritivo, de porcentagem e distribuição, utilizando o Programa Excel 2013®, para a sua elaboração. Para a análise descritiva das variáveis foram utilizadas frequências simples e porcentagens, como já mencionado.

\section{RESULTADOS E DISCUSSÕES}

Diante do cenário mundial que se vivencia com a Pandemia pelo Novo Coronavírus (SARS-CoV-2), foi preciso tomar inúmeras medidas de prevenção e controle para evitar ou reduzir ao máximo a transmissão dentro de uma Instituição Pública com o objetivo de evitar a disseminação do vírus entre os funcionários e pacientes.

No primeiro momento iniciou-se com a organização do Serviço de Saúde e orientações aos funcionários seguindo a Nota Técnica GVIMS/GGTESS/ANVISA n 04/2020. Orientações para serviços de Saúde: medidas de prevenção e controle que

RC: 93206

Disponível em: https://www.nucleodoconhecimento.com.br/saude/manifestacoes-da- 
devem ser adotadas durante a assistência aos casos suspeitos ou confirmados de infecção pelo novo Coronavírus (SARS-CoV-2).

Enfatizou-se no mês de março de 2020 as orientações sobre medidas:

- Precaução Padrão (Higienização das mãos, uso de luvas e aventais, óculos e máscara cirúrgica);

- Precaução de Contato (Higienização das mãos, avental, luvas e quarto privativo);

- Orientações sobre a colocação e retirada do EPI;

- Atendimento com critérios para triagem de sintomáticos respiratórios aos que viajaram para o exterior ou tiveram contatos a pessoas com suspeita ou positivas para COVID;

- Uso obrigatório de máscara nas dependências do Hospital Público de Açailândia e as medidas de cuidados;

- Disponibilização de máscara cirúrgica a todos os sintomáticos respiratórios que tolerem o uso da máscara;

- Transporte adequado aos pacientes com suspeita ou confirmação de COVID;

- Plano de Contingência Estadual do Coronavírus (Estado do Maranhão).

Iniciou-se as atividades Educativas entre dias 13 e 14 de março, a Educação Permanente juntamente com a $\mathrm{CClH}$ desenvolveram aos funcionários da instituição de saúde orientações relacionadas a pandemia do COVID - 19. A frequência da atividade educativa repassada para comprovação de presença, foi suspensa seguindo as orientações do Protocolo da ANVISA, suspendendo as atividades que mantivesse aumento de contato e aglomerações entre os funcionários. As atividades presenciais da Educação Permanente, estágios de todos os setores nas dependências do Hospital Público de Açailândia que estavam programados foram suspensos como medida de controle. Sendo assim, iniciou-se com orientações por meios eletrônicos (WhatsApp, Instagram oficial da prefeitura), rádios, TV dentre outros.

RC: 93206

Disponível em: https://www.nucleodoconhecimento.com.br/saude/manifestacoes-da- 
As orientações aos funcionários foram claras e objetivas com o intuito de reforçar a importância das medidas de prevenção da transmissão do Coronavírus dentro da Instituição Hospitalar e Domicílio. Utilizou-se como embasamento teórico científico os protocolos do Ministério da Saúde, Notas Técnicas GVIMS/GGTES/ANVISA, Boletim Epidemiológico $n^{\circ} 08$, Nota Técnica conjunta 01/2020: utilização e distribuição de testes rápidos para COVID-19 (CONASS- Conselho Nacional de Secretaria de Saúde) e foram tomadas medidas para fortalecer a vigilância e a assistência à saúde a todos.

No final de março chegou o primeiro caso suspeito no município, com isso foi reforçado ainda mais as orientações sobre medidas de prevenção e controle para evitar ou reduzir ao máximo a transmissão, desde então começou a organizar o fluxo de atendimento dentro da instituição conforme a demanda. Todos os funcionários que realizaram viagens interestadual, exterior ou tiveram contato com casos positivos foram isolados para cumprimento do isolamento domiciliar.

No mês de abril de 2020 foi identificado o primeiro caso confirmado de COVID-19 entre profissionais do Hospital Público de Açailândia. Com isso as medidas de contato através da redução de aglomerações foram mais rigorosas, alterando todo o contexto das orientações.

Foi reorganizado o fluxo do atendimento dentro da Unidade Hospitalar conforme as sintomatologias apresentadas por cada funcionário, como proceder para autoavaliação, agendamentos de teste rápido para COVID-19, idas ao médico e demais orientações. Com o objetivo de melhor atender a todos e evitar complicações todas as orientações e fluxogramas foram entregues aos coordenadores de cada setor do Hospital Público de Açailândia, SAMU, Setor de Transporte, alguns funcionários da secretaria de Saúde e Prefeitura.

Com o rápido crescimento no número de casos suspeitos e confirmados de COVID19, chegou-se ao pico no final do mês de abril e todo o mês de Maio, começando a

$\mathrm{RC}: 93206$

Disponível em: https://www.nucleodoconhecimento.com.br/saude/manifestacoes-da- 
regredir os casos suspeitos ou confirmados no mês de junho. A Educação Permanente foi realocada durante todo período da pandemia, dando suporte aos profissionais via celular (ligações e mensagens via WhatsApp), monitoramento da sintomatologia com o objetivo de reduzir complicações, agendamentos de teste rápido para COVID, agendamentos para avaliação médica (no início da sintomatologia, ao receber o resultado do exame e ao término do isolamento), casos observados com sintomas sugestivos de complicações foram orientados a procurar o centro de Referência no Município de origem.

A princípio o teste rápido para COVID-19 foi disponibilizado para profissionais de saúde ativos (serviços assistenciais e gestão), profissionais de segurança pública (Equipe de Corpo de Bombeiros, policiais, dentre outros) e seus familiares (com contato domiciliar) e idosos sintomáticos. É válido destacar que os testes disponíveis na época eram de anticorpos, por isso o prazo para realização dos mesmos começaram a ser agendados no $8^{\circ}$ dia após início dos sintomas conforme protocolo do CONASS, no entanto observou-se que os funcionários sintomáticos estavam apresentando testagem negativa e para segurança e retorno ao serviço começaram a testá-los no 14 dia após a data do primeiro sintomas e observou-se que alguns que negativaram no $1^{\mathrm{o}}$ teste, positivaram no $2^{\circ}$ teste, desse modo optou-se por realizar o agendamento apenas para 10 dias após a data dos primeiros sintomas. Como não estava disponível o teste rápido para COVID-19 (SARS-CoV-2) com IgG e $\lg \mathrm{M}$ e nem sorologia, fez-se uso com base de retorno das atividades profissionais pelo menos 72 horas assintomáticos, conforme boletim epidemiológico $n^{\circ} 08$.

Além da avaliação clínica dos funcionários que foram acompanhados por via celular diariamente, fez-se direcionamentos pertinentes a cada situação apresentada referente ao isolamento domiciliar, orientações a que local procurar se observassem sinais de complicações. Alguns funcionários testaram negativo no primeiro teste e posteriormente ao realizar TC de Tórax apresentaram comprometimento pulmonar

RC: 93206

Disponível em: https://www.nucleodoconhecimento.com.br/saude/manifestacoes-da- 
com aproximadamente 25 a $35 \%$, com aspecto de vidro fosco sugestivo para COVID por correlacionar com a clínica do funcionário.

A equipe médica responsável por acompanhar os funcionários foram orientadas a seguir os protocolos para atendimento aos profissionais de saúde, mesmo não sendo referência de atendimento para COVID-19, buscou-se fazer o primeiro atendimento para iniciar a terapêutica medicamentosa, solicitação de teste rápido para COVID e se necessário exames complementares. A segunda avaliação ficou no dia do teste rápido para COVID-19 para entrega de exame e reavaliação do funcionário. A terceira avaliação ficou programada para o final do afastamento do profissional e a consulta com agendamento prévio com a junta médica da Saúde do Trabalhador.

A testagem rápida de COVID-19 para familiares em contato domiciliar dos funcionários também foi agendada no laboratório do Hospital Público de Açailândia, e como essa unidade não é considerada como referência para COVID o acompanhamento médico passaram a ser agendados nas Unidades Básicas de Saúde de referência para casos leves, e para casos mais graves foram direcionados para UPA, Hospital de Campanha ou UTI nas dependências do Hospital Público de Açailândia.

Com acompanhamento diário dos profissionais de saúde a necessidade de avaliação médica foi classificada conforme a sintomatologia de cada um, quando observado complicação foram encaminhados para avaliação na UPA (observação ou mesmo a internação), podendo ser encaminhados aos leitos de isolamento do Hospital Público de Açailândia, Hospital Campanha com casos de sintomas moderados, e UTI casos graves.

A avaliação de retorno foi agendada com 15 dias ou mais, conforme o protocolo para três dias de assintomáticos para retorno ao serviço, como não tínhamos teste rápido (SARS-CoV-2) com IgG e IgM específico disponível ou mesmo a sorologia para ser

RC: 93206

Disponível em: https://www.nucleodoconhecimento.com.br/saude/manifestacoes-da- 
realizada antes do retorno, optamos usar o protocolo de retorno de profissionais da saúde ao serviço da CONASS.

Toda a equipe da direção, comissões e coordenadores se mobilizaram com o objetivo de melhor atender e orientar a todos os funcionários. Os atestados não estavam sendo entregues em mãos, apenas por e-mail e tivemos o apoio do quadro médico da Unidade Hospitalar e médico do Trabalho, todos tiveram uma enorme contribuição na avaliação dos funcionários e entrega de atestado médico para completar o período de afastamento.

Ressalta-se que mesmo diante de todas as orientações realizadas aos profissionais pode ser observada a ansiedade, angústia, o desespero e medo de contágio pelo novo Coronavírus, medo de contaminar um ente querido, medo de morte, por estarem diretamente envolvidos no processo de adoecimento e cuidados, a partir desta constatação buscou-se oferecer acompanhamento psicológico aos funcionários que necessitaram de uma escuta qualificada e obtivemos o apoio à saúde mental com a psicóloga lotada no CAPS (Centro de Atenção Psicossocial).

Temas abordados nos meses de Abril, Maio, Junho e Julho na Educação Permanente:

- Orientações para serviço de Saúde: medidas de prevenção e controle que devem ser adotadas durante a assistência aos casos suspeitos ou confirmados de infecção pelo novo Coronavírus (SARS-CoV-2);

- Lavagem das mãos, vídeos via WhatsApp;

- Emergência de Saúde Pública de importância Nacional pela doença pelo Coronavírus 2019;

- Saúde Mental e Atenção Psicossocial na pandemia COVID-2019;

- Nota Técnica referente aos cuidados da equipe de enfermagem em obstetrícia, neonatal e pediátrica diante de caso suspeito ou confirmado;

$\mathrm{RC}: 93206$

Disponível em: https://www.nucleodoconhecimento.com.br/saude/manifestacoes-da- 
- Saúde Mental e Atenção Psicossocial na pandemia COVID-2019. Recomendações para Gestores;

- Saúde Mental e Atenção Psicossocial na pandemia COVID-2019. Recomendações para o cuidado de crianças em situação de isolamento hospitalar;

- Recomendações para Ressuscitação Cardiopulmonar (RCP) de pacientes com diagnóstico ou suspeita para COVID-19;

- Orientações sobre o uso correto da máscara;

- Orientações sobre a colocação e retirada dos equipamentos de proteção individual (EPI);

- Recomendações para Ressuscitação Cardiopulmonar (RCP) de pacientes com diagnóstico ou suspeita para COVID;

- Banner informativo sobre Coronavírus: saiba como se prevenir;

- Monitoramento de eventos em Saúde Pública: Nota técnica sobre recorrência de quadro clínicos de COVID-19 em profissionais dos serviços de saúde.

No mês de agosto do ano de 2020 os casos suspeitos ou confirmados para COVID19 começaram a reduzir consideravelmente, mesmo assim foi dado continuidade ao acompanhamento de todos os funcionários por perceber a continuidade de algumas sintomatologias, porém, com menor intensidade. Com o objetivo de melhor acompanhar a todos e dar sequência ao atendimento foi elaborado um questionário pós COVID-19 para identificação de possíveis complicações.

O questionário foi elaborado em conformidade com o programa Google forms doc, tendo como tema: Avaliação dos Funcionários com Sintomatologia da COVID-19. Apenas os funcionários do Hospital Público de Açailândia que foram acompanhados de Março a Outubro receberam um link contendo a opção com respostas com múltipla escolha e algumas abertas para melhor explanação das informações. Conforme foram sendo respondidos e apresentavam alguma opção ou anotação

RC: 93206

Disponível em: https://www.nucleodoconhecimento.com.br/saude/manifestacoes-da- 
com sinal de complicação, o funcionário foi contactado por mensagem via WhatsApp ou ligação.

Todos os casos identificados como possível complicação foram encaminhados para avaliação com Cirurgião torácico/pneumologista, Cirurgião geral/vascular, ortopedista e os casos clínicos aos médicos plantonista da urgência e emergência.

Ressalta-se ainda que os coordenadores de cada setor da Unidade Hospitalar tiveram uma enorme contribuição para um melhor acompanhamento de cada funcionário.

De acordo com acompanhamento realizado junto aos profissionais que apresentaram sintomas da COVID-19, destaca-se os seguintes resultados:

Gráfico 01: Qual a sua identidade de gênero?

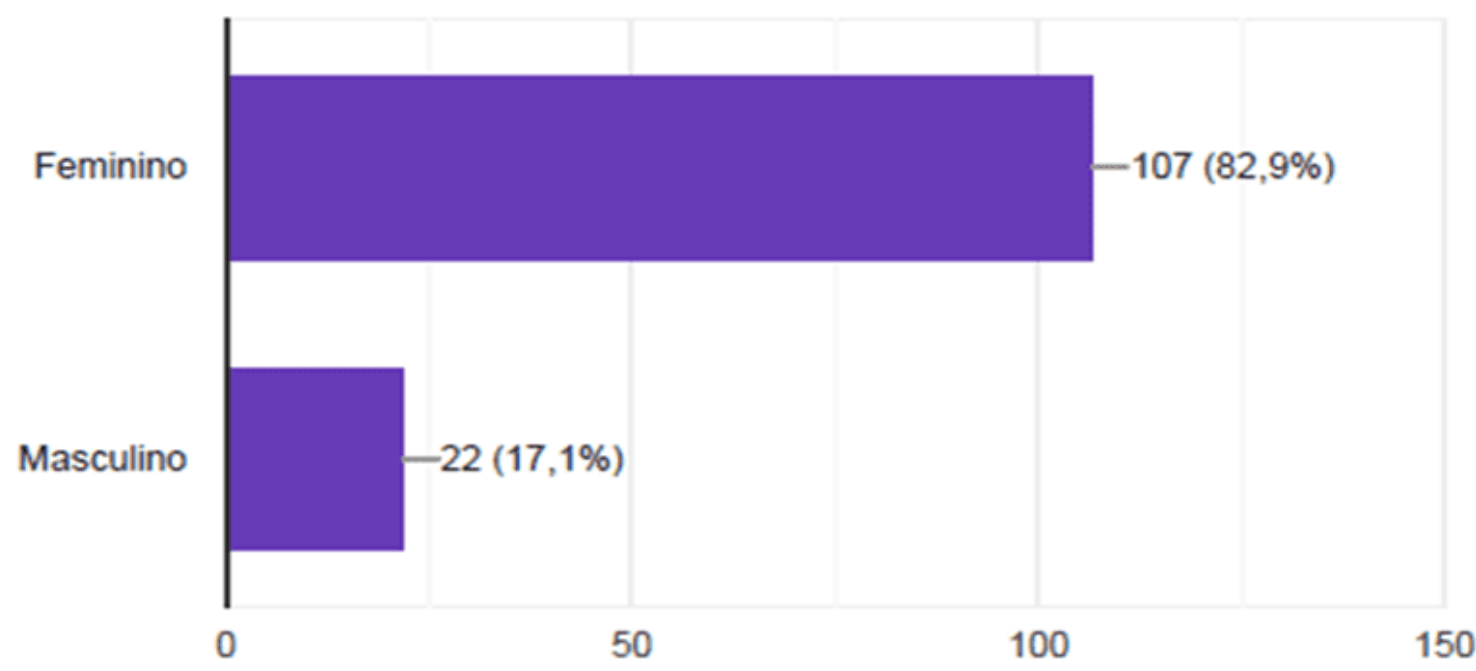

Fonte: Pesquisa de campo, Açailândia/MA - (2020).

De acordo com o primeiro gráfico apresentado, nota-se que a grande maioria dos profissionais do Hospital Público de Açailândia que apresentaram sintomas da COVID-19 são do sexo feminino, totalizando $82,9 \%$, e do sexo masculino foram

RC: 93206

Disponível em: https://www.nucleodoconhecimento.com.br/saude/manifestacoes-dacovid-19 
17,1\%. Essa informação confirma o que os estudos de uma maneira geral já vêm afirmando há muitos anos, na enfermagem a mulher exerce grande predominância.

De acordo com Neves (2020), a equipe de enfermagem é ainda predominantemente feminina, sendo composta por $84,6 \%$ de mulheres. É importante ressaltar, no entanto, que mesmo tratando-se de uma categoria feminina, registra-se a presença de $15 \%$ dos homens.

Gráfico 02: Qual a sua idade?

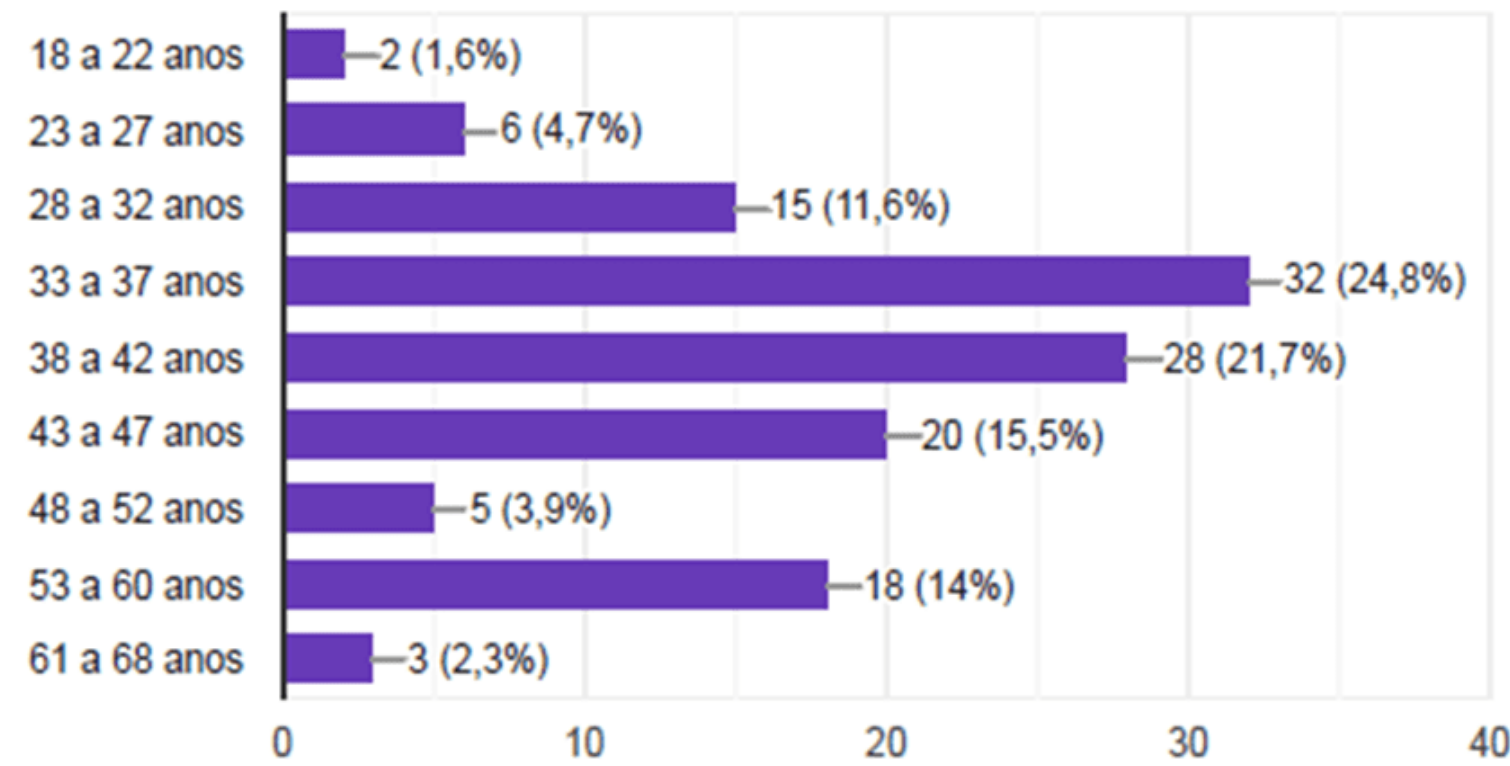

Fonte: Pesquisa de campo, Açailândia/MA - (2020).

No que diz respeito a idade, dá-se ênfase a pessoas de 33 a 37 anos $(24,8 \%)$ e de 38 a 42 anos $(21,7 \%)$. No início da pandemia, as notícias eram que os sintomas acometiam mais as pessoas idosas, e com o passar do tempo observou-se um novo contexto. A Organização Mundial da Saúde (OMS) alertou que a Covid-19, não atinge somente idosos. Medidas de prevenção e tratamento devem ser empregadas por governos e pessoas também no caso de adultos saudáveis e até mesmo de crianças (VALENTE, 2020).

RC: 93206

Disponível em: https://www.nucleodoconhecimento.com.br/saude/manifestacoes-dacovid-19 
Gráfico 03: Quais os sintomas você apresentou sugestivos da COVID-19?

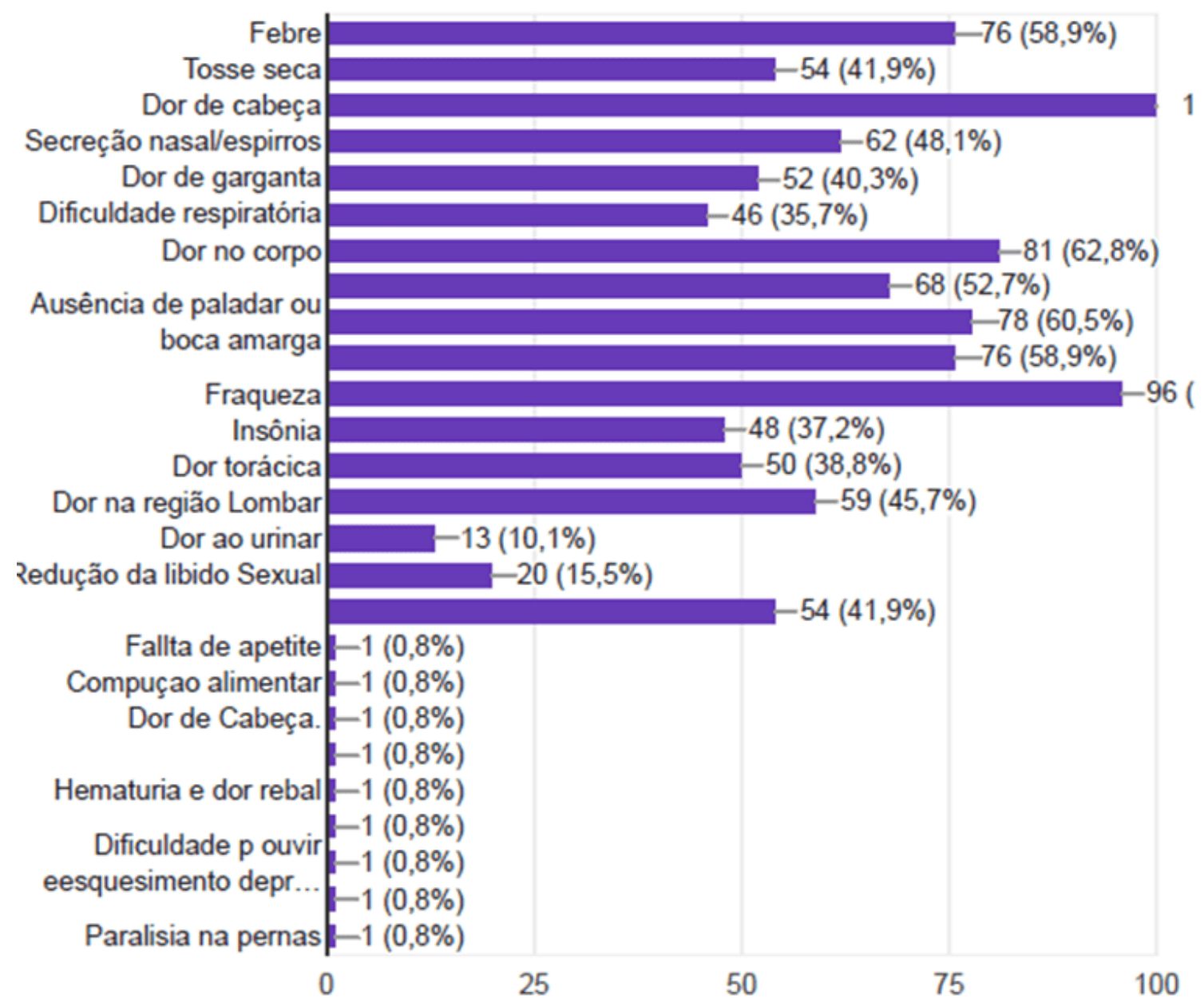

Fonte: Pesquisa de campo, Açailândia/MA - (2020).

Os sintomas apresentados pelos profissionais do Hospital Público de Açailândia são bem variados, alguns com maior incidência, importante dar destaque para os mais comuns como, febre, dor de cabeça, dor no copo, fraqueza, insônia, ausência de paladar, entre outros. De acordo com Leachi; Ribeiro (2020), a pessoa infectada pode apresentar diversos sintomas, sendo o mais frequente a febre, seguido de tosse e comprometimento pulmonar bilateral dos pulmões, que pode ser observado nas imagens de tomografia computadorizada.

RC: 93206

Disponível em: https://www.nucleodoconhecimento.com.br/saude/manifestacoes-dacovid-19 
Importante mencionar que o Hospital sempre promoveu a orientação ao funcionário diante sintomas sugestivos para COVID-19, são eles: febre; tosse seca; dor de cabeça; secreção nasal/espirros; dor de garganta; dificuldade respiratória; dor no corpo; diarreia, náuseas ou vômitos; ausência de paladar ou boca amarga e ausência do olfato.

Gráfico 04: Qual o mês iniciou os sintomas sugestivos para COVID-19?

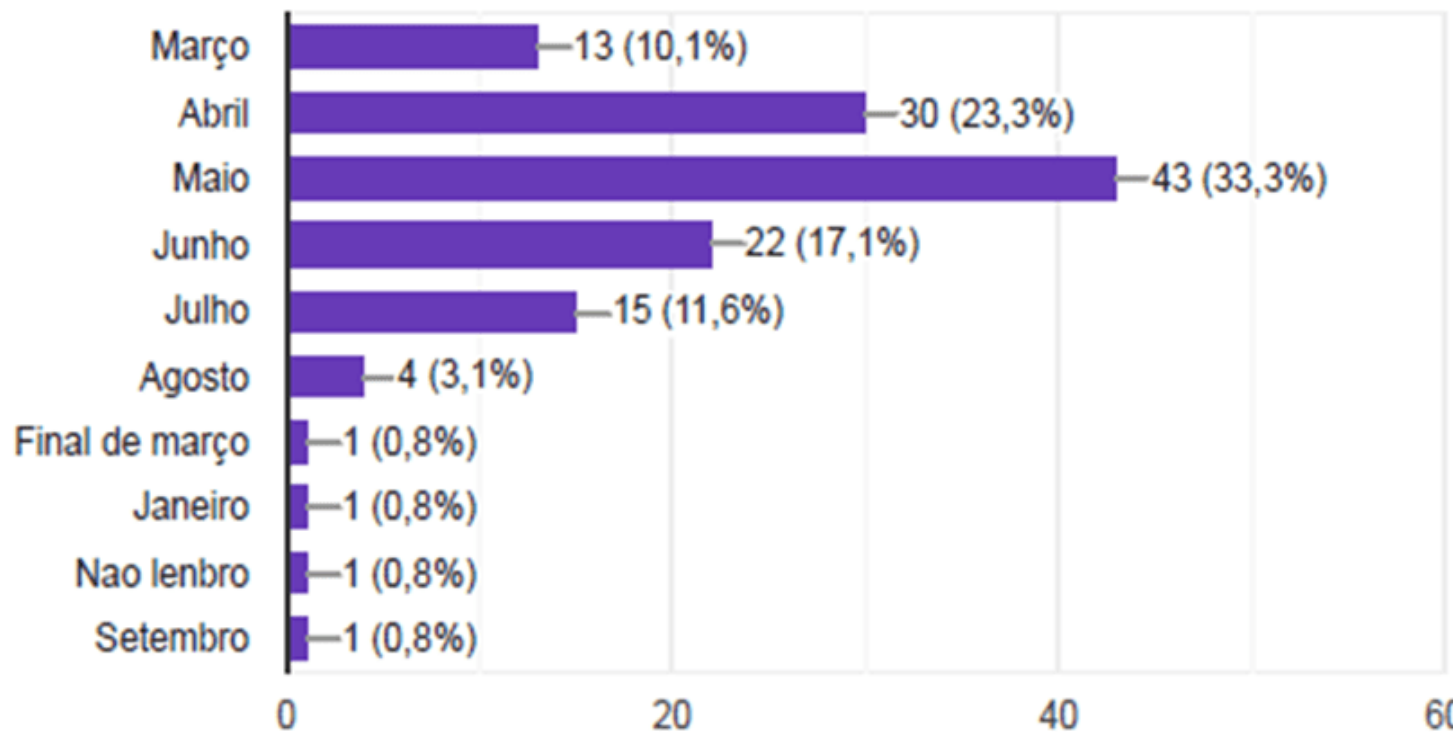

Fonte: Pesquisa de campo, Açailândia/MA - (2020).

Observou-se prevalência do número de casos no mês de maio de 2020 (33,3\%). Um fator importante se deve ao fato de boa parte dos profissionais procurar ou iniciar o tratamento precocemente. Casos suspeitos ou confirmados foram acompanhados por profissionais capacitados e dentro da própria instituição de saúde. Os casos com menor gravidade, prosseguem com 0 isolamento domiciliar e posteriormente recebem alta médica (BRASIL, 2020).

RC: 93206

Disponível em: https://www.nucleodoconhecimento.com.br/saude/manifestacoes-dacovid-19 
Gráfico 05: Qual o mês você realizou o teste para COVID-19?

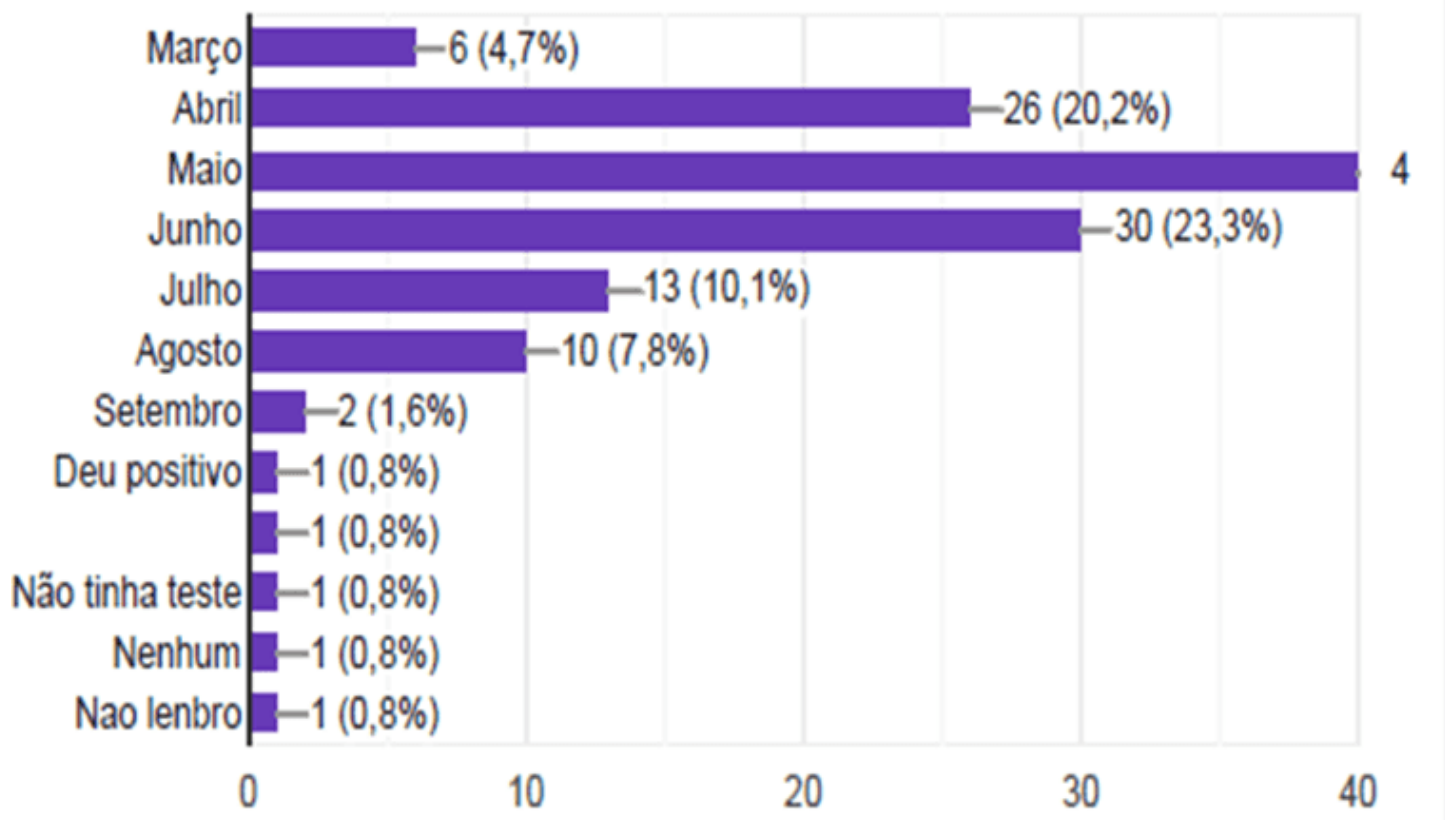

Fonte: Pesquisa de campo, Açailândia/MA - (2020).

No mês de maio foi o período em que mais profissionais realizaram o teste para COVID-19 por ser o mês de maior prevalência dos casos (33,3\%), seguido por junho $(23,3 \%)$ e abril $(20,2 \%)$. Importante destacar que somente podem ser usados os testes em casos notificados na Agência Nacional de Vigilância Sanitária, acompanhado de laudo de avaliação do Instituto Nacional de Controle de Qualidade em Saúde da Fundação Oswaldo Cruz (INCQS/Fiocruz). Além disso, o tempo de incubação é essencial para a eficácia da testagem, uma vez que pessoas infectadas, mas sem ainda manifestação de qualquer um dos sintomas, podem continuar transitando pelas cidades, havendo o risco de transmissão do vírus neste período assintomático aos contatos, sendo inclusive altamente provável que os indivíduos venham a manifestar sintomas, com a progressão da doença (BOLETIM EPIDEMIOLÓGICO 8, 2020).

RC: 93206

Disponível em: https://www.nucleodoconhecimento.com.br/saude/manifestacoes-dacovid-19 
Gráfico 06: Quais medicações você usou como tratamento para COVID-19?

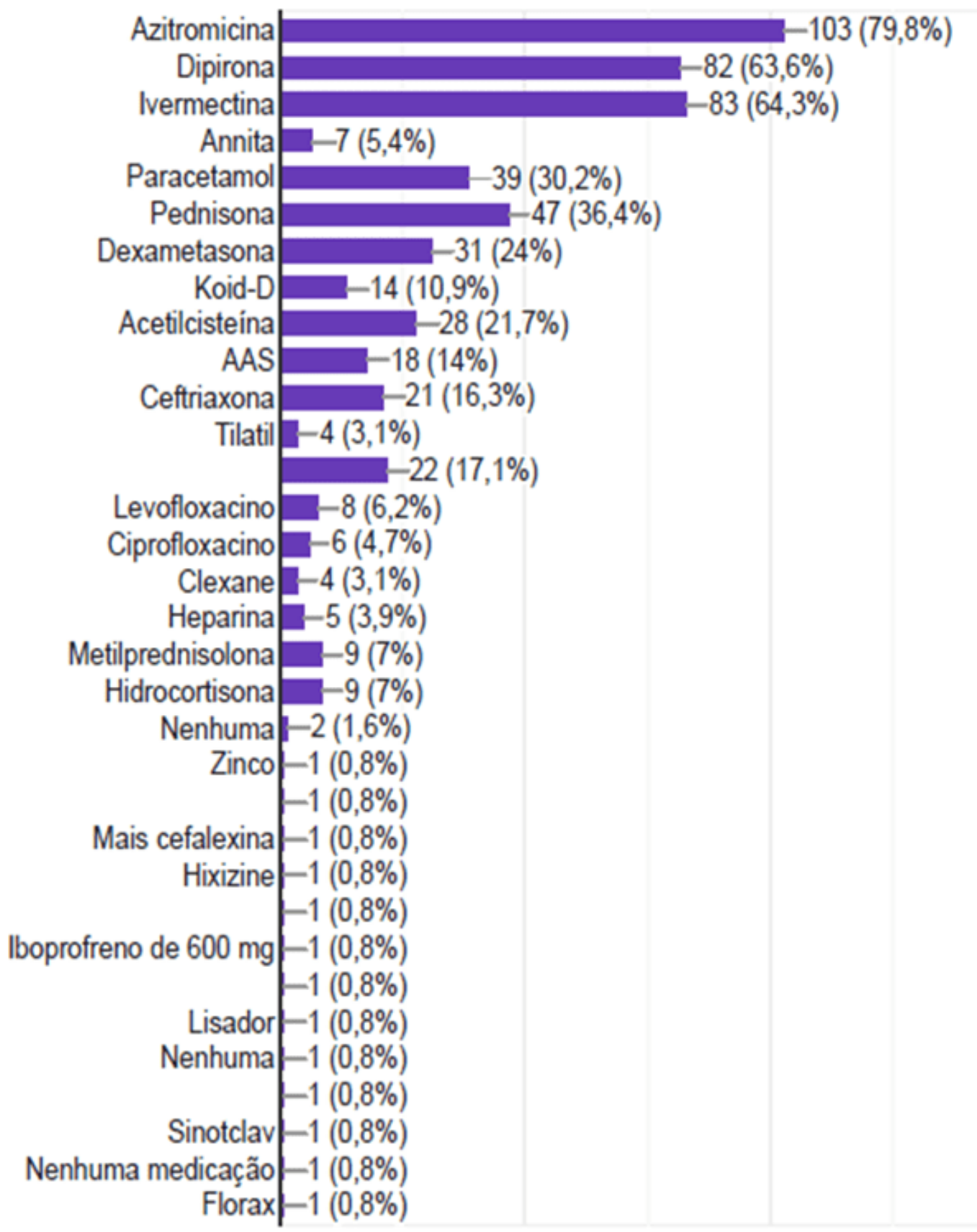

Fonte: Pesquisa de campo, Açailândia/MA - (2020).

Em relação as medicações usadas durante o tratamento para a COVID-19 pelos profissionais, destaca-se a azitromicina $(79,8 \%)$, dipirona $(63,6 \%)$, ivermectina

RC: 93206

Disponível em: https://www.nucleodoconhecimento.com.br/saude/manifestacoes-dacovid-19 
(64,3\%), entre outros. Sabe-se que ainda existe enorme falta de concordância sobre essas medicações para o tratamento da COVID-19.

Gráfico 07: Quais vitaminas você usou durante o tratamento para COVID-19?

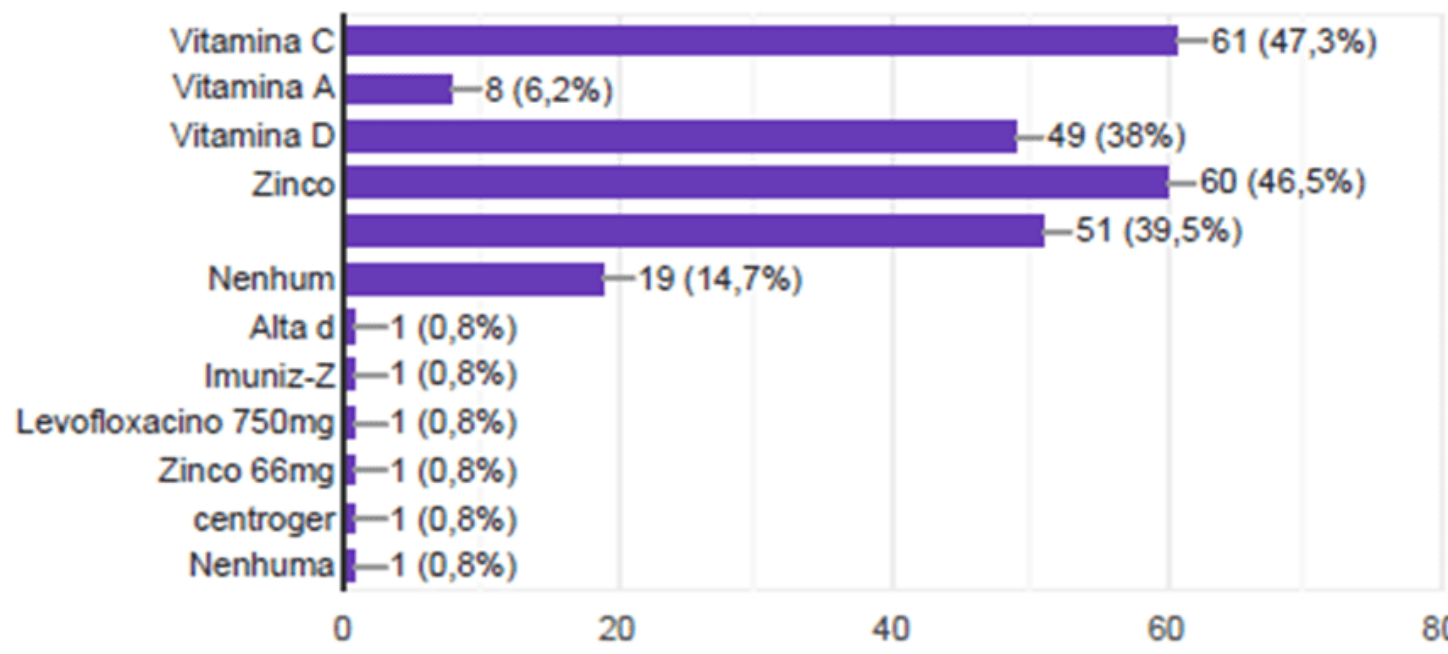

Fonte: Pesquisa de campo, Açailândia/MA - (2020).

As vitaminas mais utilizadas foram a Vitamina C, onde $47,3 \%$ fizeram uso dela, seguida da Vitamina D e do Zinco, 38\% e 46,5\% respectivamente.

RC: 93206

Disponível em: https://www.nucleodoconhecimento.com.br/saude/manifestacoes-dacovid-19 
Gráfico 08: Quanto tempo você ficou afastado do serviço?

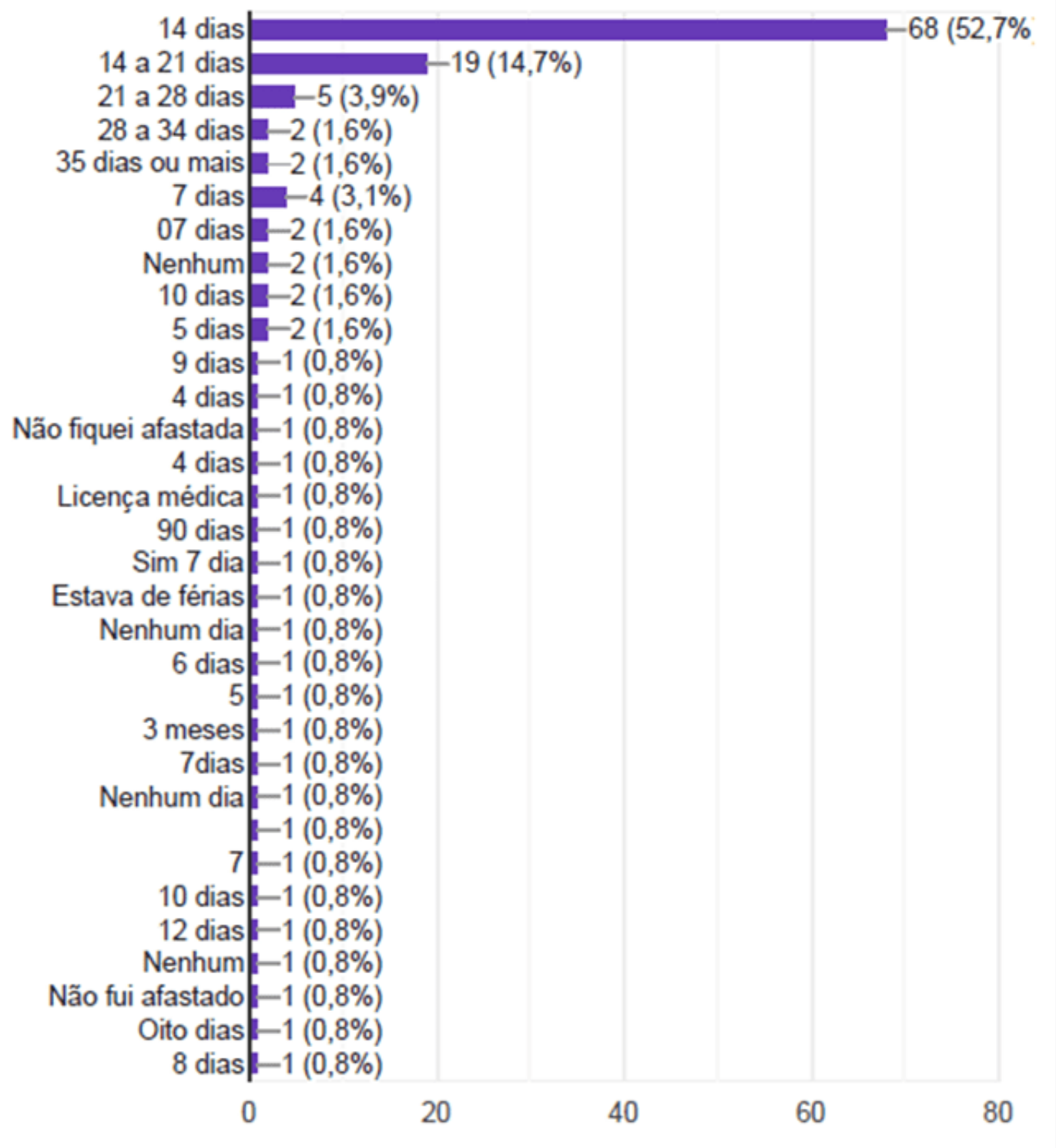

Fonte: Pesquisa de campo, Açailândia/MA - (2020).

A maior parte dos funcionários, totalizando $52,7 \%$, precisaram ficar 14 afastados do trabalho, outros por mais tempo, até 21 dias, totalizando $14,7 \%$ dos trabalhadores.

RC: 93206

Disponível em: https://www.nucleodoconhecimento.com.br/saude/manifestacoes-dacovid-19 
O principal obstáculo da saúde que atinge os trabalhadores que se encontram em cuidado direto aqueles infectados pelo COVID-19 consiste na alta chance de serem contaminados pelo vírus. Existem diversos fatores que evidenciam o elevado grau de exposição e contágio dos trabalhadores da área de saúde (TEIXEIRA et al., 2020).

Os trabalhadores que ofertam suas habilidades diariamente aos serviços de saúde, também acabam ficando expostos a cargas de trabalho que são consideradas extremamente desgastantes e estressantes, provocando um adoecimento. Essas cargas recebem classificações, são elas: biológicas, químicas, físicas, mecânicas, fisiológicas e psíquicas (SILVA; FERRAZ; JÚNIOR, 2017).

RC: 93206

Disponível em: https://www.nucleodoconhecimento.com.br/saude/manifestacoes-dacovid-19 
Gráfico 09: Possui alguma doença crônica?

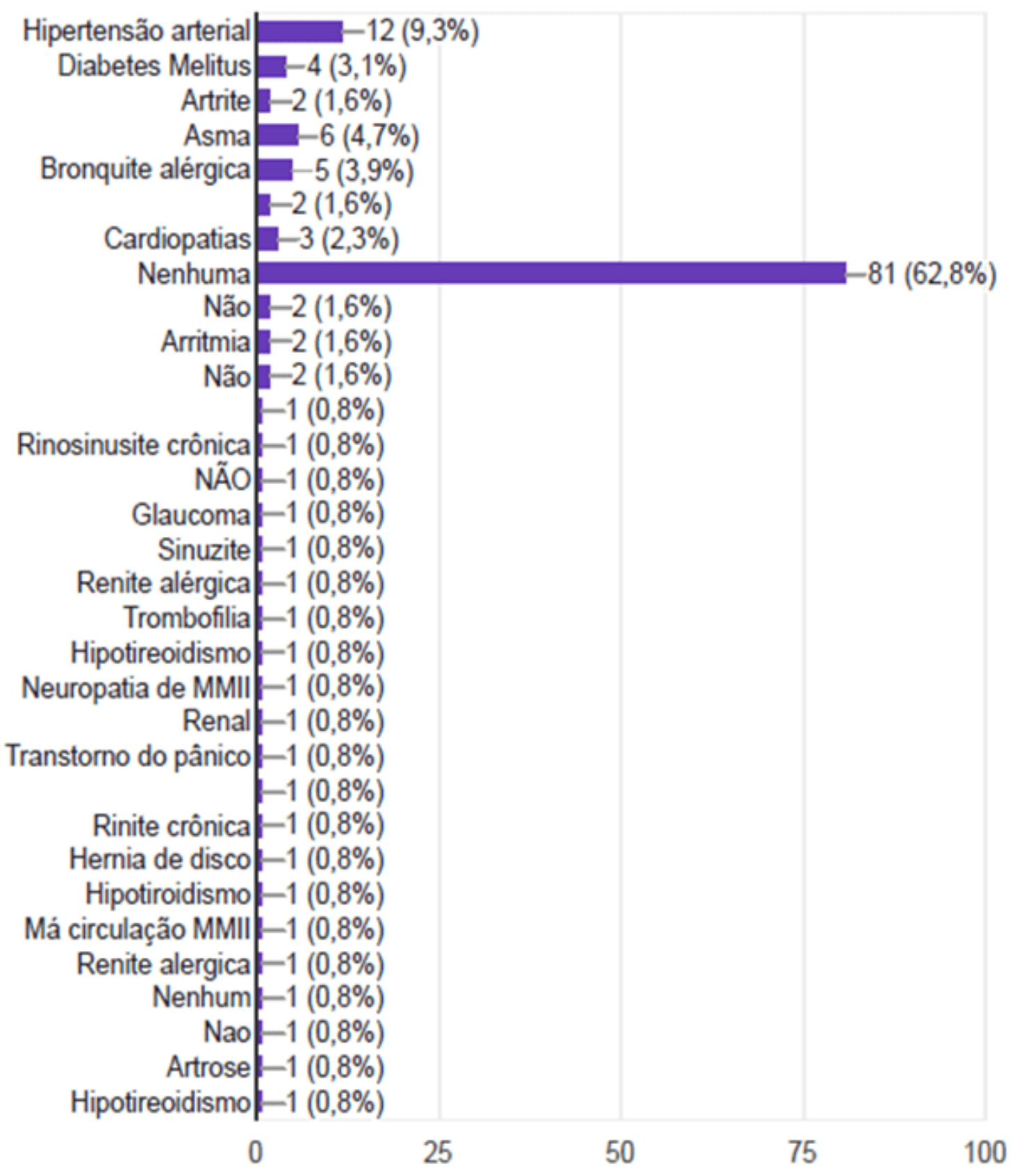

Fonte: Pesquisa de campo, Açailândia/MA - (2020).

A maioria dos trabalhadores, ou seja, $62,8 \%$ não possuíam nenhuma doença crônica, apenas uma minoria tinha hipertensão arterial, diabetes mellitus, artrite,

RC: 93206

Disponível em: https://www.nucleodoconhecimento.com.br/saude/manifestacoes-dacovid-19 
asma, bronquite alérgica etc. É importante definir o termo doença crônica, ele é usado para designar patologias com um ponto em comum: conhecidos por serem persistentes e por necessitarem de cuidados permanentes.

A hipertensão arterial é a doença crônica de maior prevalência na população, ocasionando altas taxas de mortalidade e morbidade e se faz necessário tratamento de manutenção da doença por toda a vida. Dentre os fatores de risco para a hipertensão, temos o estilo de vida caracterizado por alimentação falha, hábitos de ingerir bebidas alcoólicas, fumar, complementado pelo sedentarismo (ANDRADE et al., 2015).

Diabetes mellitus é uma doença crônica que faz parte de um grupo de doenças metabólicas manifestando-se através do aumento da glicemia ou defeito na secreção de insulina pelos pâncreas e/ou defeito na ação da insulina em órgãos alvos (SBD, 2016).

RC: 93206

Disponível em: https://www.nucleodoconhecimento.com.br/saude/manifestacoes-dacovid-19 
Gráfico 10: Faz uso de medicação contínua? Se for sim, qual?

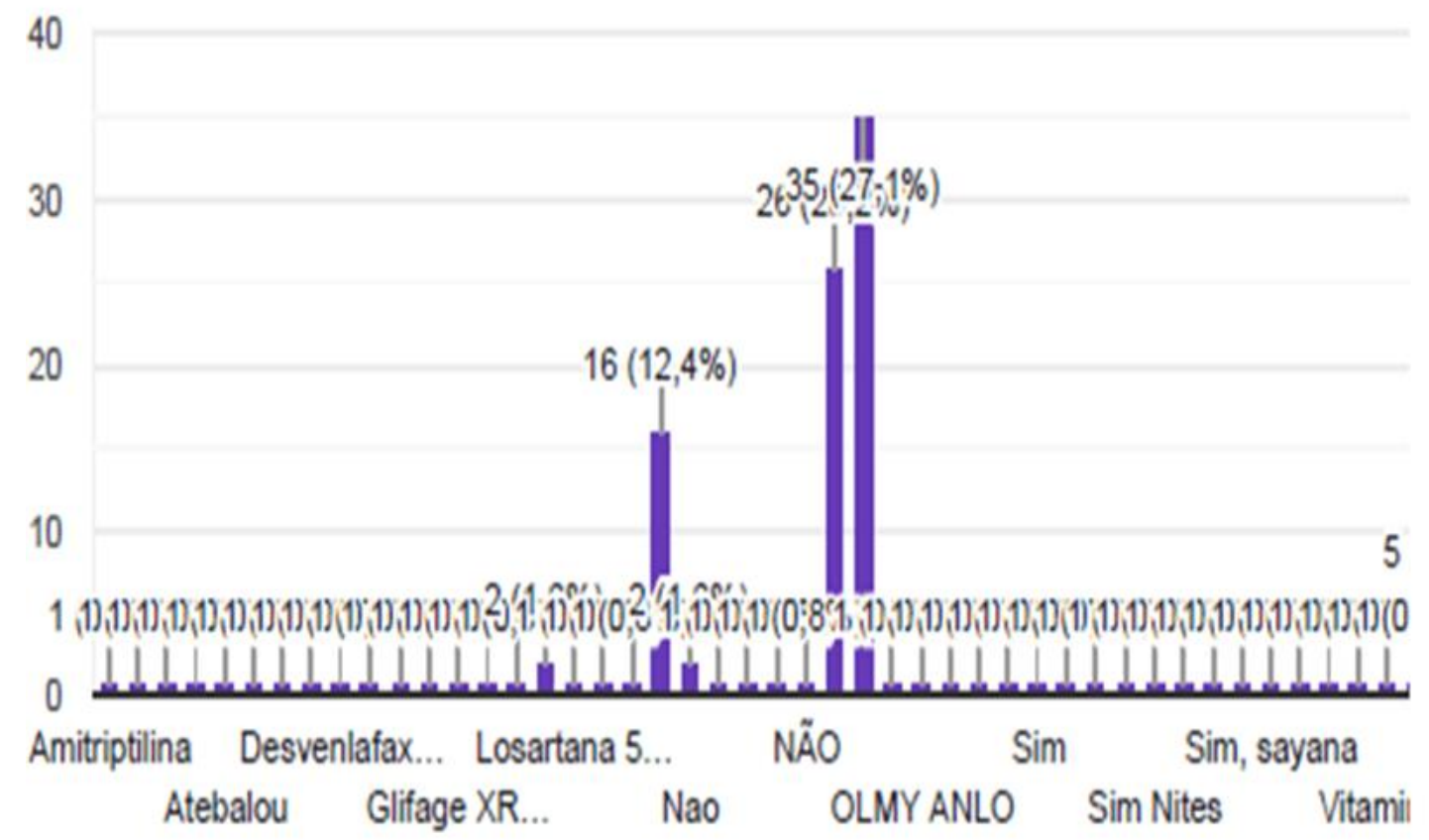

Fonte: Pesquisa de campo, Açailândia/MA - (2020).

Os profissionais continuaram fazendo uso da medicação, por boa parte de tempo, haja vista, sendo acompanhados e avaliados de forma gradual. Além disso, os profissionais foram orientados a nunca fazer a automedicação.

RC: 93206

Disponível em: https://www.nucleodoconhecimento.com.br/saude/manifestacoes-dacovid-19 
Gráfico 11: Houve a necessidade de buscar atendimento hospitalar durante a COVID-19 além das avaliações agendadas?

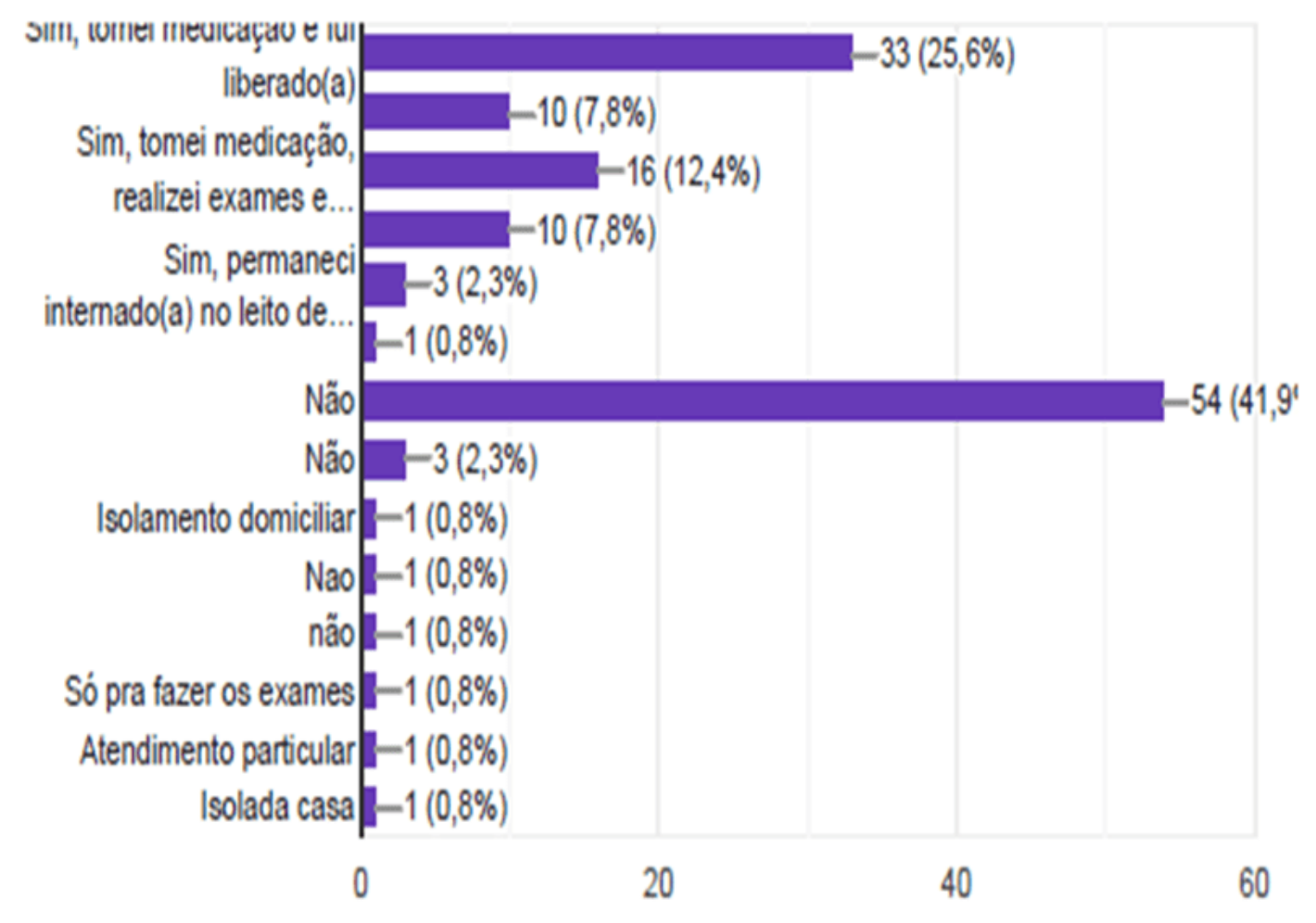

Fonte: Pesquisa de campo, Açailândia/MA - (2020).

Nesse questionamento pode-se perceber que grande parte dos profissionais, totalizando $41,9 \%$ não necessitou buscar atendimento hospitalar durante a COVID19 além das avaliações agendadas.

Vale salientar que foi reorganizado o fluxo do atendimento dentro da Unidade Hospitalar conforme as sintomatologias apresentadas por cada funcionário, como proceder para autoavaliação, agendamentos de teste rápido para COVID-19, idas ao médico e demais orientações.

RC: 93206

Disponível em: https://www.nucleodoconhecimento.com.br/saude/manifestacoes-dacovid-19 
Com o objetivo de melhor atender a todos e evitar complicações todas as orientações e fluxogramas foram entregues aos coordenadores de cada setor do Hospital Público de Açailândia, SAMU, Setor de Transporte, alguns funcionários da secretaria de Saúde e Prefeitura.

Gráfico 12: Se houve necessidade de internação hospitalar após complicação pela COVID-19 qual o motivo?

[caption

$$
\text { id="attachment_93220" }
$$

align="aligncenter"

width="815"]

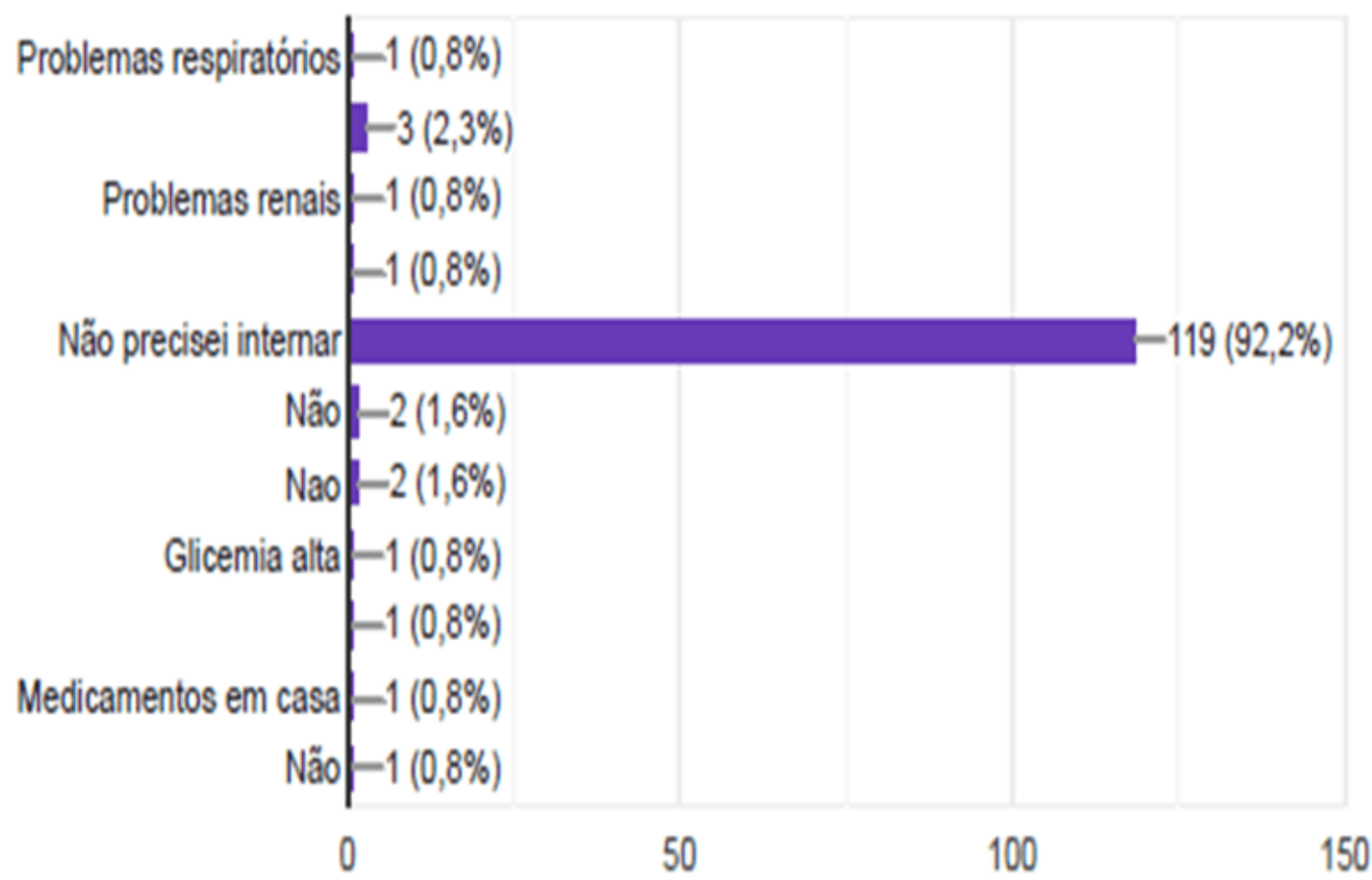

Fonte: Pesquisa de campo, Açailândia/MA - (2020).

Somente 2,3\% tiveram necessidade de internação hospitalar, por outro lado, 92,2\% não precisaram se internar, pois foi importante todo o suporte oferecido pelo Hospital Público de Açailândia a esses profissionais.

RC: 93206

Disponível em: https://www.nucleodoconhecimento.com.br/saude/manifestacoes-dacovid-19 
Lembrando que foi realizado acompanhamento diário dos profissionais de saúde a necessidade de avaliação médica foi classificada conforme a sintomatologia de cada um, quando observado complicação foram encaminhados para avaliação na UPA, unidade de referência no município em questão (observação ou mesmo a internação), podendo ser encaminhados aos leitos de isolamento do Hospital Público de Açailândia ou Hospital Campanha com casos de sintomas moderados, e UTI casos graves.

RC: 93206

Disponível em: https://www.nucleodoconhecimento.com.br/saude/manifestacoes-dacovid-19 
Gráfico 13: Quais exames você realizou durante o acompanhamento no primeiro mês da COVID-19?

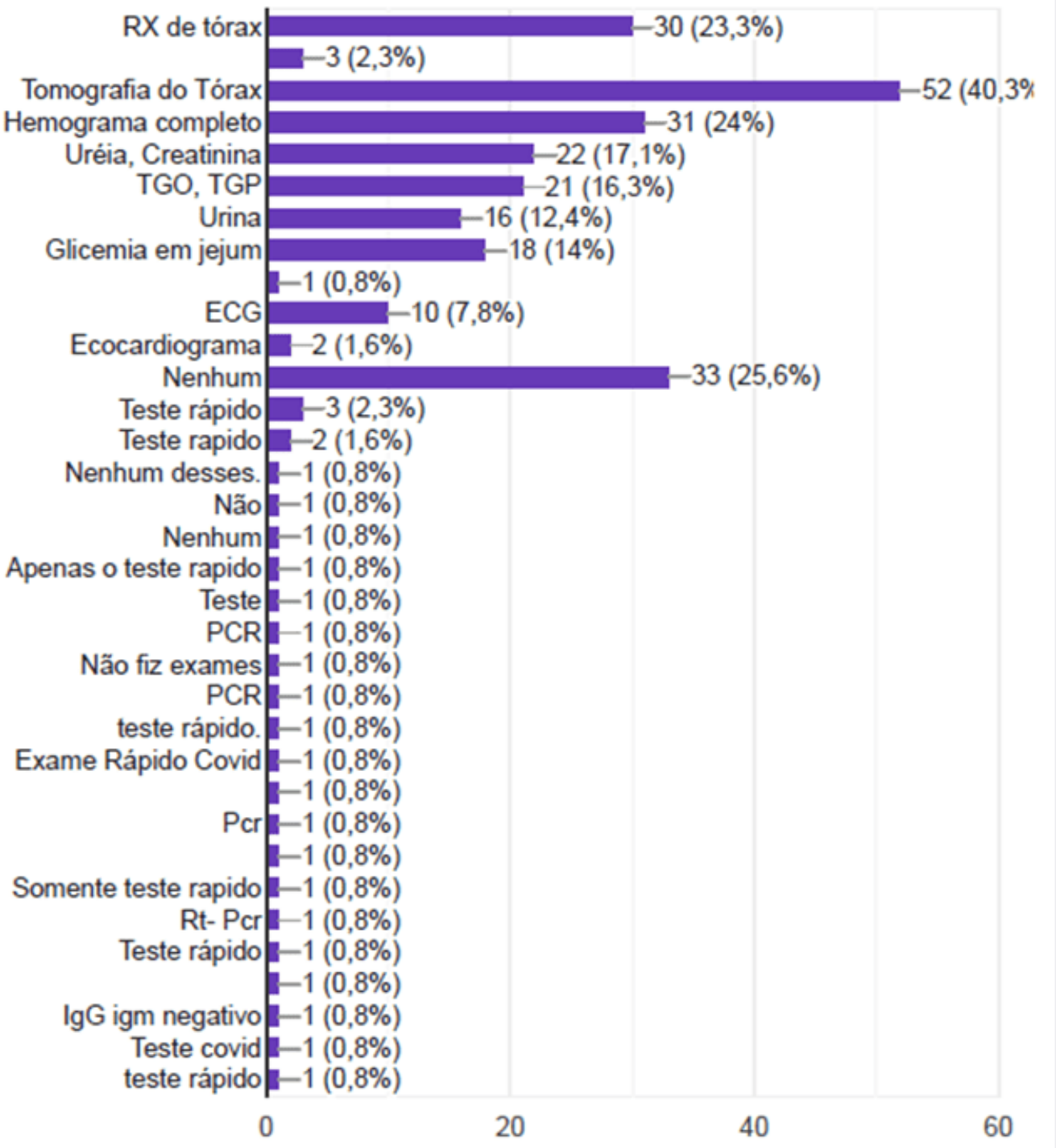

Fonte: Pesquisa de campo, Açailândia/MA - (2020).

Os principais exames foram de Raio X de tórax, tomografia, entre outros, porém, alguns profissionais não realizam exames, esses totalizaram 25,6\%. Buscou-se fazer um acompanhamento diário de todos os funcionários conforme a necessidade, avaliação psicológica em casos específicos, exames laboratoriais, $\mathrm{RX}$, Tomografia

RC: 93206

Disponível em: https://www.nucleodoconhecimento.com.br/saude/manifestacoes-dacovid-19 
de tórax dentre outros. O município disponibilizou a entrega de kits para COVID, deixando na Farmácia Interna facilitando o acesso aos funcionários, a princípio sendo entregues em 05 Unidades Básicas de Saúde que foram preparadas para receber a população em geral com quadros suspeitos ou confirmados para COVID, e posteriormente entregues na Farmácia Básica localizada na Secretaria Municipal de Saúde.

Gráfico 14: Quais os sintomas você apresentou sugestivos para a COVID-19 após os 14 dias de iniciados os primeiros sintomas?

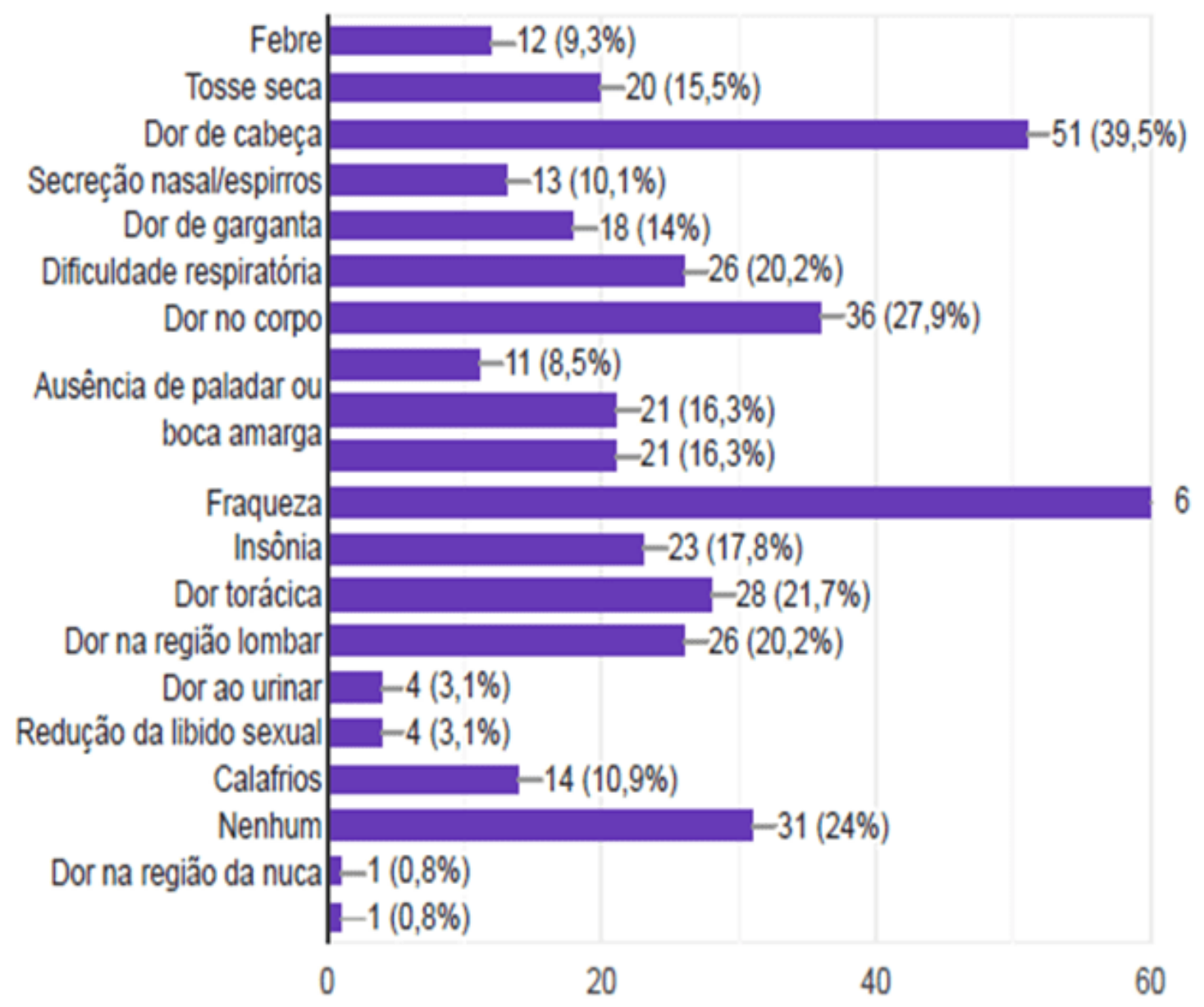

Fonte: Pesquisa de campo, Açailândia/MA - (2020).

RC: 93206

Disponível em: https://www.nucleodoconhecimento.com.br/saude/manifestacoes-dacovid-19 
Mesmos após os 14 dias, alguns sintomas persistiram, entre eles febre, tosse seca, dor de cabeça, fraqueza, entre outros, porém, $24 \%$ não apresentou mais nenhuma queixa.

Gráfico 15: Ainda está fazendo uso de alguma medicação após a COVID-19? Se sim, qual?

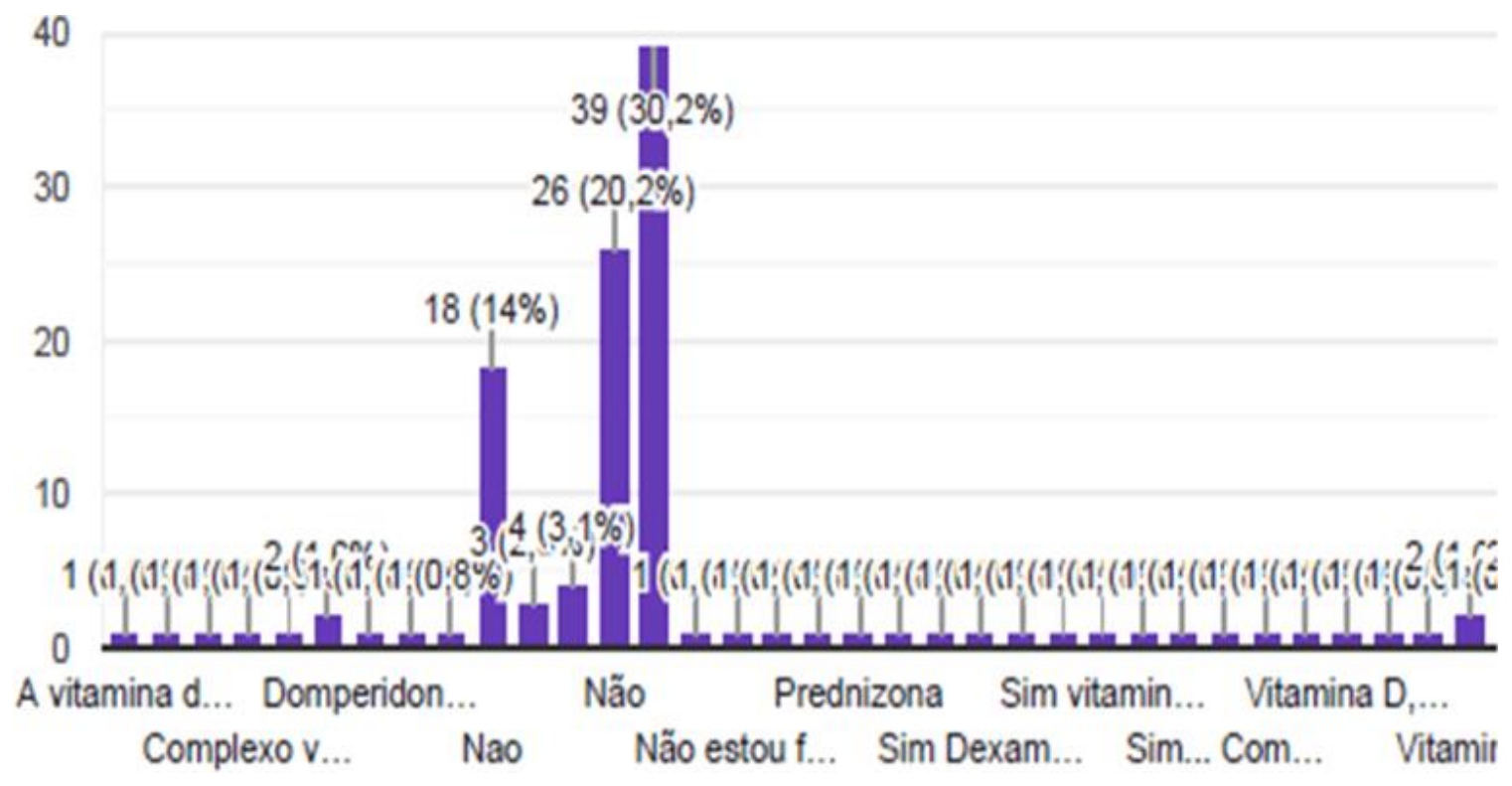

Fonte: Pesquisa de campo, Açailândia/MA - (2020).

São poucos os funcionários que seguiram fazendo uso de alguma medicação, quando acontecia, era a domperidona, vitamina $\mathrm{D}$ etc.

RC: 93206

Disponível em: https://www.nucleodoconhecimento.com.br/saude/manifestacoes-dacovid-19 
Gráfico 16: Se você repetiu o exame para COVID-19 (teste rápido ou RT-PCR) após os 14 dias de iniciados os primeiros sintomas, qual foi o mês?

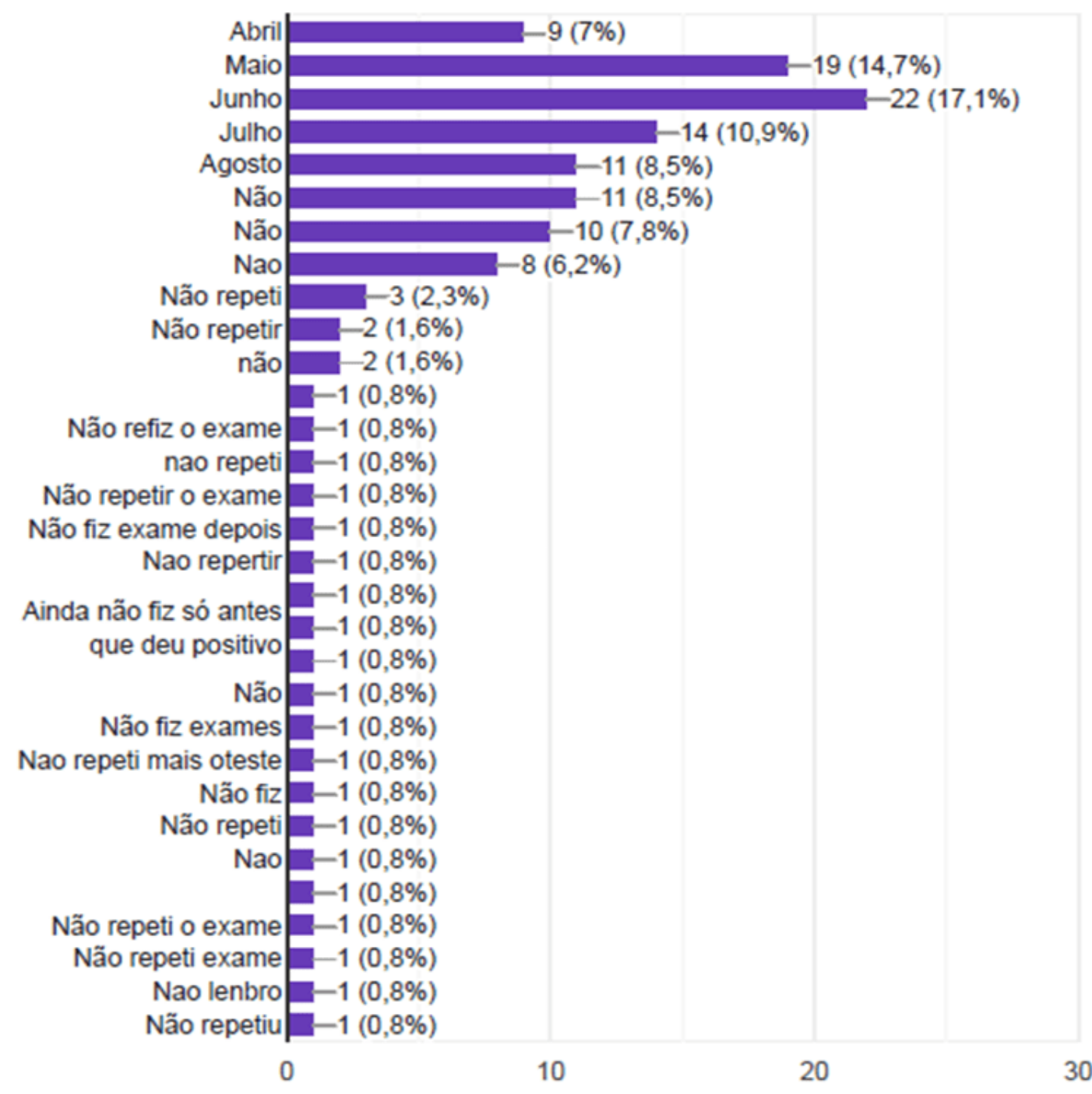

Fonte: Pesquisa de campo, Açailândia/MA - (2020).

Quanto a repetição do exame para COVID-19 (teste rápido ou PCR) após os 14 dias de iniciados os primeiros sintomas, o mês mais citado foi junho, representando $17,1 \%$.

RC: 93206

Disponível em: https://www.nucleodoconhecimento.com.br/saude/manifestacoes-dacovid-19 
A taxa de transmissão dos trabalhadores infectados pelo SARS-CoV é comumente de 7 dias depois da manifestação dos sintomas. Contudo, informações preliminares do Novo Coronavírus (2019-nCoV) indicam que a contaminação possa acontecer, mesmo que seja assintomática. Até então, não existem dados o bastante para definir quantos dias precedentes a manifestação dos sintomas o sujeito infectado passa a propagar o vírus (BRASIL, 2020).

Gráfico 17: Se você repetiu o exame para COVID-19 (teste rápido ou PCR) após os 14 dias de iniciados os primeiros sintomas, qual foi o resultado?

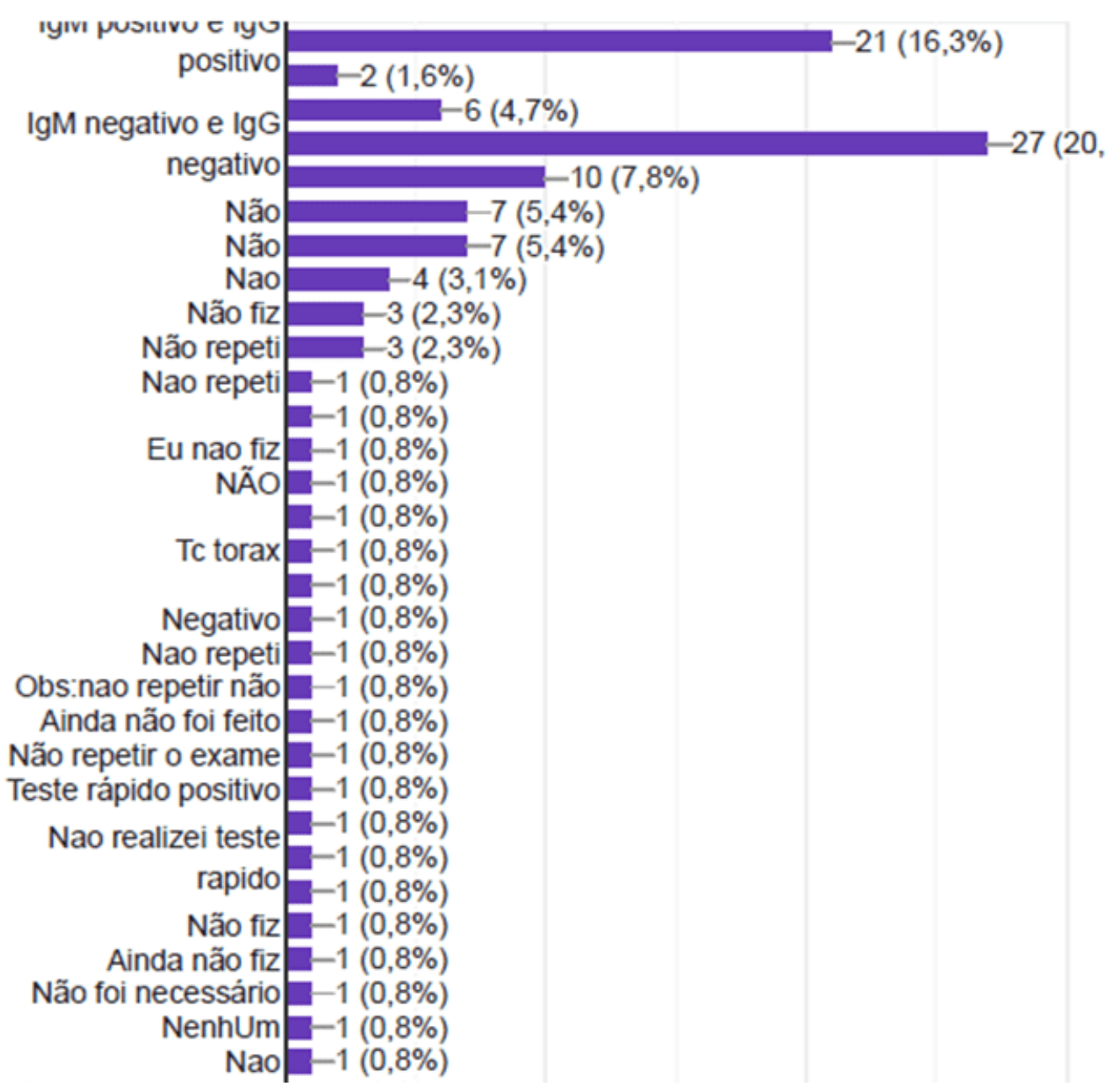

Fonte: Pesquisa de campo, Açailândia/MA - (2020).

RC: 93206

Disponível em: https://www.nucleodoconhecimento.com.br/saude/manifestacoes-dacovid-19 
Boa parte dos resultados, depois de repetir o exame para COVID-19 (teste rápido ou PCR) após os 14 dias de iniciados os primeiros sintomas, foi negativo, totalizando $20 \%$.

Gráfico 18: De 01 a 10 como você classifica a sua saúde após a COVID-19?

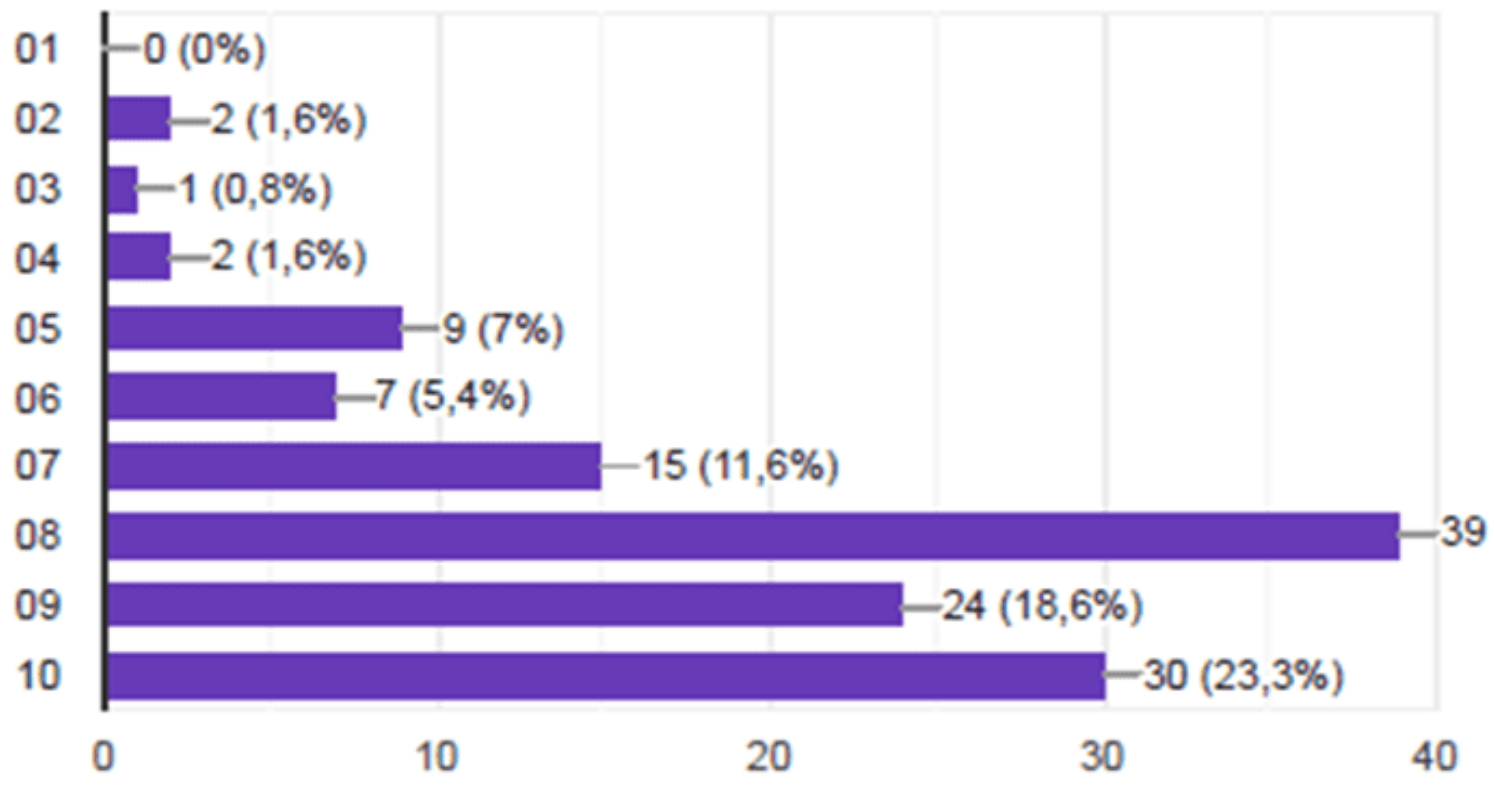

Fonte: Pesquisa de campo, Açailândia/MA - (2020).

A recuperação da COVID-19 ainda é uma incógnita, porém, boa parte dos profissionais ainda relataram uma saúde que não atinge os $100 \%$, precisando ainda de maior tempo para sua recuperação.

\section{CONSIDERAÇÕES FINAIS}

Alguns cuidados são essenciais para a prevenção da COVID-19, e os mesmos foram diariamente pontuados junto a Instituição Pública, principalmente pelos profissionais, que estão na linha de frente, são eles: lavagem das mãos, vídeos via WhatsApp; Saúde Mental e Atenção Psicossocial na pandemia COVID-2019; orientações para afastamento e retorno às atividades de profissionais de saúde;

RC: 93206

Disponível em: https://www.nucleodoconhecimento.com.br/saude/manifestacoes-dacovid-19 
Cartilha de Isolamento Domiciliar; orientações nutricionais para fortalecer o sistema imunológico dos profissionais de saúde; autoavaliação dos profissionais para identificação dos sintomas de COVID-19; Banner informativo sobre Coronavírus: saiba como se prevenir e Orientações sobre o uso correto da máscara.

O acompanhamento com os funcionários sintomáticos foi finalizado no mês de outubro de 2020, passando assim qualquer caso confirmado ou suspeito para ser acompanhado apenas pela parte clínica hospitalar e os agendamentos de teste rápido sendo realizados diretamente no laboratório conforme apresentação da solicitação médica.

Os casos de complicações continuaram com acompanhamento e agendamento com os médicos do Hospital Público de Açailândia com objetivo de melhor atender a todos. Assim, todos os documentos preenchidos durante o acompanhamento dos funcionários foram arquivados no setor de $\mathrm{RH}$.

Os documentos arquivados poderão futuramente ser utilizados como fonte de pesquisas bibliográficas para publicação de artigos científicos conforme liberação da diretoria geral da Instituição de Saúde.

A Instituição Pública de Saúde continuará mantendo os cuidados necessários preconizados pelo Ministério da Saúde/ANVISA para medidas de controle da disseminação do vírus e evitar um novo ciclo de infecção dentro da Unidade de Hospitalar de Saúde.

Conclui-se que o funcionário quando acompanhado desde o início dos sintomas, a complicação foi menor, e o acompanhamento diário por um profissional por 14 dias ou mais, foi de suma importância para evitar maiores complicações. Percebeu-se que quando existe um envolvimento da equipe multiprofissional, acompanhamento psicológico e o paciente não é tratado somente como a doença em si, obtém-se um melhor prognóstico.

RC: 93206

Disponível em: https://www.nucleodoconhecimento.com.br/saude/manifestacoes-da- 
O período de maior angústia foi predominante principalmente no início da pandemia, março, abril e maio de 2020 foram os meses mais críticos, e o mês de maio e junho foi o mês em que foi constatado o maior número de casos de COVID-19 entre funcionários.

\section{REFERÊNCIAS}

ANVISA - AGÊNCIA NACIONAL DE VIGILÂNCIA SANITÁRIA. Nota Técnica GVIMS/GGTES/ANVISA № 06/2020. Orientações para a prevenção e o controle das infecções pelo Novo Coronavírus (SARS-CoV-2) em procedimentos cirúrgicos Revisão: 29.05.2020.

ANVISA - AGÊNCIA NACIONAL DE VIGILÂNCIA SANITÁRIA. Nota Técnica GVIMS/GGTES/ANVISA № 07/2020. Orientações para a prevenção da transmissão de COVID-19 dentro dos serviços de saúde. Brasília, 08 de maio de 2020.

ANVISA - AGÊNCIA NACIONAL DE VIGILÂNCIA SANITÁRIA. Nota Técnica GVIMS/GGTES/ANVISA № 04/2020. Orientações para serviços de saúde: medidas de prevenção e controle que devem ser adotadas durante a assistência aos casos suspeitos ou confirmados de infecção pelo Novo Coronavírus (SARS-CoV-2). Atualizada em 08/05/2020.

ANVISA - AGÊNCIA NACIONAL DE VIGILÂNCIA SANITÁRIA. Nota Técnica GVIMS/GGTES/ANVISA № 08/2020. Orientações gerais para implantação das práticas de segurança do paciente em hospitais de campanha e nas demais estruturas provisórias para atendimento aos pacientes durante a pandemia de COVID-19. Brasília, 13 de maio de 2020.

ANVISA - AGÊNCIA NACIONAL DE VIGILÂNCIA SANITÁRIA. Nota Técnica GVIMS/GGTES/ANVISA № 05/2020. Orientações para a prevenção e o controle de

RC: 93206

Disponível em: https://www.nucleodoconhecimento.com.br/saude/manifestacoes-dacovid-19 
infecções pelo Novo Coronavírus (SARS-CoV-2) em instituições de Longa Permanência para Idosos (ILPI). Atualizada em 24/06/2020.

ANVISA - AGÊNCIA NACIONAL DE VIGILÂNCIA SANITÁRIA. Nota Técnica Pública CSIPS/GGTES/ANVISA № 01/2020. Orientações para a prevenção e o controle de infecções pelo Novo Coronavírus (SARS-CoV-2) em instituições de acolhimento. 24 de junho de 2020.

ANDRADE, Silvânia Suely de Araújo, et al. Prevalência de hipertensão arterial autorreferida na população brasileira: análise da Pesquisa Nacional de Saúde, 2013. Epidemiol. Serv. Saúde, Brasília, 24(2): 297-304, abr-jun 2015.

BRASIL. MINISTÉRIO DA SAÚDE. Secretaria de Atenção Especializada à Saúde. Departamento de Atenção Hospitalar, Domiciliar e de Urgência. Protocolo de manejo clínico da Covid-19 na Atenção Especializada [recurso eletrônico] / Ministério da Saúde, Secretaria de Atenção Especializada à Saúde, Departamento de Atenção Hospitalar, Domiciliar e de Urgência. - 1. ed. rev. - Brasília: Ministério da Saúde, 2020.

BRASIL. Secretaria de Vigilância em Saúde/Ministério da Saúde. Boletim epidemiológico. Doença pelo coronavírus 2019. 09 de abril de 2020/Semana Epidemiológica 15 (05-10/04).

BRASIL. Ministério da Saúde. Protocolo de Tratamento do Novo Coronavírus (2019-nCoV). Brasília - DF, 2020.

BRASIL. Ministério da Saúde. Diretrizes para diagnóstico e tratamento da COVID-19. Brasília - DF, 08 de abril de 2020.

ESTADO DO MARANHÃO. Secretaria de Estado da Saúde. Nota informativa CIEVS № 04/2020. São Luís, 13 de abril de 2020.

RC: 93206

Disponível em: https://www.nucleodoconhecimento.com.br/saude/manifestacoes-dacovid-19 
GIL, Antonio Carlos. Metodologia do ensino superior. 4. ed. São Paulo: Atlas, 2011.

Instituto Brasileiro de Geografia e Estatística - IBGE. Açailândia. Disponível em: https://cidades.ibge.gov.br/brasil/ma/acailandia/panorama. Acesso em: 25/03/2021.

LEACHI, H.F.L, RIBEIRO, R.P. Máscaras utilizadas pelos profissionais da saúde: o que é recomendado? Advances in Nursing and Health. [Internet]. 2020;2(1):2-7.

Disponível em: http://www.uel.br/revistas/uel/index.php/anh/article/view/39757/27114. Acesso em: 26/03/2021.

NEVES, Úrsula. Perfil da enfermagem no Brasil: pesquisa faz levantamento da profissão. Disponível em: https://pebmed.com.br/perfil-da-enfermagem-no-brasilpesquisa-faz-levantamento-da-profissao/. Acesso em: 25/03/2021.

OLIVEIRA, Edith Cibelle de. Et al. Sintomas clínicos de pacientes recuperados da COVID-19 em regiões da Amazônia Oriental. Revista Científica Multidisciplinar Núcleo do Conhecimento. Ano 05, Ed. 11, Vol. 04, pp. 57-65. Novembro de 2020.

PREFEITURA MUNICIPAL DE AÇAILÂNDIA. Secretaria Municipal de Saúde. Orientações para o isolamento domiciliar. Comitê Municipal de Prevenção, de Combate e Monitoramento ao COVID-19, 2020.

PREFEITURA MUNICIPAL DE AÇAILÂNDIA. Secretaria Municipal de Saúde. Plano Municipal de Contingência. Secretaria de Saúde de Açailândia Novo Coronavírus (COVID-19). Açailândia - MA, 2020.

RICHARDSON, Roberto Jarry. Pesquisa social: métodos e técnicas. São Paulo: Atlas, 1999.

RC: 93206

Disponível em: https://www.nucleodoconhecimento.com.br/saude/manifestacoes-dacovid-19 
SANTOS, José Natanael Gama dos, et al. Perfil dos profissionais de saúde acometidos pela covid19 no estado do Amapá-Norte-Brasil. Jornal de Ciências da Saúde - JCS HU-UFPI. Ed. Espec. 2020; 3(Supl.2):e-11288.

SANTOS, Genilson Gaudêncio dos. Et al. Atuação de enfermeiros no combate à COVID-19 no Estado da Paraíba: Um relato de experiência. Revista Científica Multidisciplinar Núcleo do Conhecimento. Ano 05, Ed. 11, Vol. 10, pp. 05-15. Novembro de 2020.

SOCIEDADE BRASILEIRA DE DIABETES. Diretrizes da Sociedade Brasileira de Diabetes- SBD $\quad$ 2019-2020. Disponível em: $<$ https://www.diabetes.org.br/profissionais/images/diretrizes-completa-20192020.pdf>. Acesso em: 05/03/2021.

SILVA, Andressa; FERRAZ, Lucimare; JUNIOR, Sinval Adalberto Rodrigues. Ações em Saúde do Trabalhador desenvolvidas na Atenção Primária no município de Chapecó, Santa Catarina. Revista Brasileira de Saúde Ocupacional, 2016.

TEIXEIRA, Carmen Fontes de Souza, et al. A saúde dos profissionais de saúde no enfrentamento da pandemia de Covid- 19. Ciência \& Saúde Coletiva, 25(9): 34653474, 2020.

VALENTE, Jonas. Covid-19 não é doença somente de idosos, alerta OMS. Disponível em: https://agenciabrasil.ebc.com.br/saude/noticia/2020-03/covid-19-naoe-doenca-somente-de-idosos-alerta-oms. Acesso em: 25/03/2021.

WORLD HEALTH ORGANIZATION. Novel Coronavirus (COVID-19) Situation. 2020. Disponível em: https://who.maps.arcgis.com/ Acesso em: 08/02/2021.

Enviado: Junho, 2021.

Aprovado: Agosto, 2021.

RC: 93206

Disponível em: https://www.nucleodoconhecimento.com.br/saude/manifestacoes-dacovid-19 